\title{
Advanced glycation end products (AGEs) and other adducts in aging-related diseases and alcohol-mediated tissue injury
}

\author{
Wiramon Rungratanawanich', Ying Qu' ${ }^{1}$ Xin Wang ${ }^{2}$, Musthafa Mohamed Essa ${ }^{3,4}$ and Byoung-Joon Song ${ }^{1}$
}

\begin{abstract}
Advanced glycation end products (AGEs) are potentially harmful and heterogeneous molecules derived from nonenzymatic glycation. The pathological implications of AGEs are ascribed to their ability to promote oxidative stress, inflammation, and apoptosis. Recent studies in basic and translational research have revealed the contributing roles of AGEs in the development and progression of various aging-related pathological conditions, such as diabetes, cardiovascular complications, gut microbiome-associated illnesses, liver or neurodegenerative diseases, and cancer. Excessive chronic and/or acute binge consumption of alcohol (ethanol), a widely consumed addictive substance, is known to cause more than 200 diseases, including alcohol use disorder (addiction), alcoholic liver disease, and brain damage. However, despite the considerable amount of research in this area, the underlying molecular mechanisms by which alcohol abuse causes cellular toxicity and organ damage remain to be further characterized. In this review, we first briefly describe the properties of AGEs: their formation, accumulation, and receptor interactions. We then focus on the causative functions of AGEs that impact various aging-related diseases. We also highlight the biological connection of AGE-alcohol-adduct formations to alcohol-mediated tissue injury. Finally, we describe the potential translational research opportunities for treatment of various AGE- and/or alcohol-related adduct-associated disorders according to the mechanistic insights presented.
\end{abstract}

\section{Introduction}

Advanced glycation end products (AGEs) are potentially harmful heterogeneous molecules of irreversible products derived from nonenzymatic glycation. Reactions involving nonenzymatic glycation occur between the reactive carbonyl group of a reducing sugar and nucleic acids, lipids, or proteins. AGEs can be formed endogenously or provided by exogenous sources under normal and pathological conditions ${ }^{1,2}$. The pathological implications of AGEs

\footnotetext{
Correspondence: Wiramon Rungratanawanich (wiramon.

rungratanawanich@nih.gov) or Byoung-Joon Song (bj.song@nih.gov)

'Section of Molecular Pharmacology and Toxicology, Laboratory of Membrane Biochemistry and Biophysics, National Institute on Alcohol Abuse and

Alcoholism, 9000 Rockville Pike, Bethesda, MD 20892, USA

${ }^{2}$ Neuroapoptosis Drug Discovery Laboratory, Department of Neurosurgery,

Brigham and Women's Hospital, Harvard Medical School, 60 Fenwood Road, Boston, MA 02115, USA

Full list of author information is available at the end of the article
}

are ascribed to their ability to produce reactive oxygen (ROS) and nitrogen (RNS) species, as well as oxidative stress and inflammation, leading to structural and functional protein alterations, cellular dysfunction and apoptosis, and ultimately multitissue/organ injuries ${ }^{3}$. Crosslinks formed by the interactions of AGEs with their cell surface receptors for advanced glycation end products (RAGEs) have been found during the development and progression of various aging-related diseases, such as diabetes, cardiovascular complications, kidney malfunctions, osteoporosis, cancer, neurodegenerative diseases, and liver disorders ${ }^{4,5}$

Alcohol (ethanol), one of the most addictive substances consumed by billions of people, has been found to cause more than 200 diseases and injuries worldwide ${ }^{6,7}$. In the United States alone, more than 250 billion dollars are lost annually due to alcoholism-related disorders and their

\section{(c) The Author(s) 2021}

(c) (i) Open Access This article is licensed under a Creative Commons Attribution 4.0 International License, which permits use, sharing, adaptation, distribution and reproduction cc) in any medium or format, as long as you give appropriate credit to the original author(s) and the source, provide a link to the Creative Commons license, and indicate if changes were made. The images or other third party material in this article are included in the article's Creative Commons license, unless indicated otherwise in a credit line to the material. If material is not included in the article's Creative Commons license and your intended use is not permitted by statutory regulation or exceeds the permitted use, you will need to obtain permission directly from the copyright holder. To view a copy of this license, visit http://creativecommons.org/licenses/by/4.0/. 
consequences $^{8}$. In addition, multiple millions of global deaths have been reported from excessive alcohol consumption due to acute and long-term consequences such as accidents, injuries, and a wide range of diseases ${ }^{7,9}$. Chronic misuse of alcohol promotes damage to multiple tissues and organs. It can lead to the development of various pathological states, such as alcohol use disorder, alcoholic liver disease, and alcohol-related brain damage, as well as increase the risk of cancer in the gastrointestinal tract, respiratory tract, breast, and liver ${ }^{10,11}$. However, despite the considerable amount of research in this area, the underlying molecular mechanisms by which alcohol exerts its cellular toxicity and organ damage remain to be further characterized.

In this review, we first briefly describe the properties of AGEs: their formation, accumulation, and RAGE interactions. We then focus on the causative functions of AGEs that impact various aging-related diseases. In addition, we highlight the biological connections of AGE-alcohol-adduct formations in alcohol-mediated multiorgan damage. Finally, we briefly describe the potential translational research opportunities for treating various AGE- and/or alcohol-related adduct-associated disorders based on the mechanistic insights presented.

\section{AGE formation}

\section{Endogenous AGEs}

Endogenous AGEs represent adducts that are produced and slowly accumulated within the body during the normal aging process and under the oxidative stress, inflammatory, and hyperglycemic (high blood sugar) conditions often observed in diabetes and other metabolic syndromes ${ }^{1,4,12,13}$. AGEs are formed by a nonenzymatic glycation reaction, also known as the Maillard reaction, between the carbonyl group of a reducing sugar and a free amino group ( $\mathrm{N}$-terminus, lysine, or arginine residue) of proteins or (adenine or guanine) of nucleic acids. This reaction is followed by a highly reversible nucleophilic addition reaction to generate a reversible Schiff base adduct, which is rearranged to a more stable and covalently bound Amadori product (e.g., hemoglobin A1c). Then, the Amadori product undergoes rearrangement, dehydration, and oxidation reactions to form irreversible products, AGEs, in the body. In addition to nonenzymatic glycation, AGEs can be formed through the polyol pathway and lipid peroxidation in the presence and absence of hyperglycemia, depending on the substrate type, reactant concentration, exposure time, and host cellular context ${ }^{14-}$ 17 .

Various factors are involved in promoting AGE formation. These factors include excessive and/or prolonged alcohol consumption, cigarette smoking, the intake of high fat/caloric diets and/or extensively processed food, renal status, homeostatic imbalance, inflammation, hyperglycemia, and oxidative stress $^{2-4}$. For example, persistently high blood glucose, often observed in people with type 2 diabetes, increases the reservoir of substrate for accelerating AGE formation and activates protein kinase $\mathrm{C}$ and NADPH oxidases, producing $\mathrm{ROS}^{13,18}$. Additionally, elevated oxidative stress can act as a catalyst to stimulate AGE accumulation, while activation of AGEs can increase oxidative stress, creating a synergistic feedforward loop to accelerate pathophysiological conditions $^{2-4}$.

\section{Exogenous AGEs}

Exogenous AGEs include dietary AGEs (e.g., foods and beverages such as soft drinks containing high fructose corn sirup and/or sugar) and cigarette smoke. Additionally, dietary AGEs can be produced during food preparation. This formation of dietary AGEs depends on various factors, such as (1) temperature. e.g., the food browning process; (2) water content. e.g., dry-heat cooking; (3) $\mathrm{pH}$ status, e.g., food processing at high $\mathrm{pH}$; and (4) cooking time and method, e.g., long-term cooking or storage and frying or broiling. These variations activate the nonenzymatic Maillard reaction, leading to the formation of glycation products and AGEs ${ }^{5,19}$. For example, high heat and prolonged cooking time enhance the rate and amount of AGE production in $\operatorname{diets}^{20}$. Foods with high $\mathrm{pH}$ values (up to 10) have elevated AGEs due to free amino groups under alkaline conditions ${ }^{21}$. Putative examples of dietary AGEs are modern Western diets such as bakery goods, breakfast cereals, cheese, and meat cooked by a dry-heat method ${ }^{22}$. In addition to dietary AGEs, cigarette smoke is found to contain reactive glycation products, which can increase AGE accumulation in the tissues and circulating blood of smokers ${ }^{23}$.

The amounts of AGEs in exogenous sources are usually much higher than those of endogenously produced $\mathrm{AGEs}^{2-4,24}$. Thus, it is likely that the intake of foods and/ or beverages with high levels of exogenous AGEs create more health problems than endogenously produced AGEs, although both exogenous and endogenous AGEs are similar in their biological functions and potentially act synergistically to stimulate oxidative stress, inflammation, and cellular damage, contributing to detrimental pathophysiology ${ }^{2-4,24}$.

\section{AGE accumulation}

\section{Intracellular AGEs}

AGEs gradually accumulate during the aging process through normal metabolic and glycation activities. The aggregation of AGEs from endogenous and/or exogenous sources can negatively affect the functions of many cells in the entire body, resulting in diverse cellular responses and ultimately cellular damage and degeneration. Intracellular AGE accumulation can stimulate 
aberrant protein glycation, abnormal protein folding, and the aggregation of irregular or oligomeric proteins, as well as elevated oxidative stress and inflammation and upregulated apoptotic signaling pathways. These changes can contribute to protein inactivation, endoplasmic reticulum (ER) stress, mitochondrial dysfunction, cell apoptosis, and organ damage ${ }^{25,26}$. For instance, in neuronal tissues, the accumulation of AGEs induces glycation of $\alpha$-synuclein and tau proteins, leading to protein dysfunction accompanied by the aggregation of harmful protein oligomers capable of initiating and developing neurodegenerative diseases $^{27,28}$.

\section{Extracellular AGEs}

AGEs are long-lived irreversibly formed molecules found in the circulatory system and tissues, particularly those with long-lasting proteins such as lens crystallins, cartilage, glomerular basement membrane, and extracellular matrix ${ }^{29,30}$. Cross-linking AGEs with extracellular matrix proteins, including laminin, elastin, and collagen, can alter the elasticity and function of tissues. In fact, higher levels of AGE cross-links are commonly detected in experimental animal models and autopsied tissue samples from people who are aging or have cancer, obesity, or diabetic complications ${ }^{31-33}$. In addition to longlived proteins, AGEs can bind to proteins with short halflives such as serum albumin, thereby activating RAGEs and inducing inflammatory responses followed by protein dysfunction and cell damage ${ }^{34}$.

\section{RAGEs and other AGE receptors}

A RAGE is a multiligand cell surface receptor in the immunoglobulin superfamily ${ }^{35}$. Generally, RAGEs are expressed widely in various cells, such as endothelial cells, macrophages/monocytes, neutrophils, lymphocytes, microglia, astrocytes, and neurons, and organs, such as the brain, heart, lung, kidney, and liver ${ }^{36,37}$. However, under pathological conditions, RAGEs can be upregulated and participate in various aging-related pathophysiologies, such as adult-onset type 2 diabetes mellitus (DM), cardiovascular disorders, myocardial infarction, chronic kidney failure, pancreatitis, cancer, Alzheimer's disease (AD), Parkinson's disease (PD), hepatic fibrosis, and alcohol-mediated tissue injury ${ }^{37,38}$.

The interaction of AGE-RAGE triggers intracellular and extracellular signaling pathways through the activation of extracellular signal-regulated kinases 1 and 2 (ERK1/2), mitogen-activated protein kinases (MAPK), phosphoinositide 3-kinase (PI3K), protein kinase B (AKT), NADPH oxidase, and nuclear factor- $\mathrm{kB}(\mathrm{NF}-\mathrm{\kappa} \mathrm{B})$. Activation of these proteins usually increases oxidative stress and inflammation that, in turn, promotes RAGE expression in a positive feed-forward loop, contributing to chronic disease development ${ }^{39-41}$. In addition to an AGE, a RAGE binds diverse ligands, such as members of the $\mathrm{S} 100$ protein family, amyloid- $\beta$ peptides $(A \beta)$, prions, and high-mobility group protein B1 (HMGB1), which alter cellular functions and contribute to various pathophysiologies ${ }^{42-44}$.

In addition to RAGEs, AGEs can interact with other cell surface receptors that possess the opposite function of RAGEs. These AGE cell surface receptors include AGER1, AGE-R2, AGE-R3, and scavenger receptors such as macrophage scavenger receptors, scavenger receptor class B type I and II (SR-BI, SR-BII), and cluster of differentiation 36 (CD36). The interaction of AGEs with these receptors can enhance their catabolism and clearance by modulating endocytosis and degradation ${ }^{45,46}$, suggesting a potentially adaptive defensive mechanism in the body to reduce the detrimental effects of increased glycation products.

\section{AGEs and aging-related diseases (see summary in Table 1) \\ AGEs and diabetes}

Chronic hyperglycemia, frequently observed in experimental models and human diabetes, exhibits elevated AGE formation, serum AGE levels, RAGE expression, and AGE-RAGE interactions. Consequently, these changes lead to increased oxidative stress, insulin resistance, inflammation, pancreatic $\beta$-cell dysfunction with apoptosis, and eventually diabetic complications, including retinopathy, neuropathy, cardiomyopathy, microvascular complications, and nephropathy ${ }^{47-50}$.

Dietary AGEs have been found to disrupt and downregulate sirtuin1 (SIRT1) expression, resulting in the acetylation and inactivation of peroxisome proliferatoractivated receptor $\gamma$ coactivator-1 $\alpha$ (PGC1 $\alpha$ ), a master regulator of mitochondrial metabolism. AGEs also stimulate mitochondrial ROS production and c-Jun Nterminal protein kinase (JNK) and NADPH oxidase activity to induce mitochondrial dysfunction and oxidative stress ${ }^{51-53}$. Furthermore, increased oxidative stress and JNK/MAPK expression can contribute to pancreatic $\beta$-cell dysfunction with apoptosis, glucose-induced insulin secretion impairment, and subsequent insulin resistance, which is a key hallmark of type $2 \mathrm{DM}^{54}$. Restriction of dietary AGEs can reduce and/or reverse these effects by enhancing insulin sensitivity and upregulating AGE-R1 and SIRT1 expression while suppressing NF- $\mathrm{kB}$, tumor necrosis factor-alpha (TNF- $\alpha$ ), leptin, and serum AGEs in type $2 \mathrm{DM}^{55}$.

AGEs play important roles in diabetic microvascular complications by cross-linking with extracellular matrix proteins, thereby altering vascular elasticity, structure, and function ${ }^{56}$. In addition, the AGE-RAGE interaction further instigates pericyte apoptosis, vascular inflammation and permeability, and blood-tissue barrier breakdown $^{56}$. In contrast, the inhibition of RAGE by RAGE 
Table 1 Summary of the AGEs and AGE-RAGE interaction in aging-related diseases.

\begin{tabular}{|c|c|c|}
\hline Diseases & Mechanisms & Consequences \\
\hline Diabetes & $\begin{array}{l}\downarrow \text { SIRT1, active PGC1a } \\
\uparrow \text { ROS, MAPK (JNK), NADPH oxidase }\end{array}$ & $\begin{array}{l}\uparrow \text { oxidative stress, inflammation, mitochondrial dysfunction } \\
\uparrow \text { pancreatic } \beta \text {-cell dysfunction and apoptosis, insulin resistance, } \\
\text { glucose -induced insulin secretion impairment= diabetic } \\
\text { complications }^{51-55}\end{array}$ \\
\hline $\begin{array}{l}\text { - Diabetic microvascular } \\
\text { complications }\end{array}$ & $\uparrow$ extracellular matrix glycation & $\begin{array}{l}\downarrow \text { vascular elasticity } \\
\uparrow \text { vascular inflammation and permeability and blood-tissue barrier } \\
\text { breakdown } \\
\uparrow \text { pericyte apoptosis }{ }^{56,57}\end{array}$ \\
\hline Cardiovascular diseases & $\begin{array}{l}\text { AGEs } \equiv \text { mononuclear, endothelial, and } \\
\text { smooth muscle cells } \\
\text { RAGE } \equiv \text { HMGB1 and S100 } \\
\uparrow \text { MAPK }\end{array}$ & $\begin{array}{l}\uparrow \text { oxidative stress and inflammation } \\
\uparrow \text { oxidation of LDLs } \\
\uparrow \text { cardiomyocyte dysfunction, apoptosis, and tissue damage } \\
=\text { severity of coronary atherosclerosis and coronary artery disease }\end{array}$ \\
\hline Kidney diseases & $\begin{array}{l}\text { RAGE } \equiv \text { HMGB1 } \\
\uparrow \text { extracellular matrix glycation } \\
\uparrow \text { proximal tubular senesces } \\
\uparrow \text { NF-KB, MAPK, PKC, ERK1/2, MCP-1, TNF-a, IL- } \\
\quad 6, \text { CTGF, TGF- } \beta\end{array}$ & $\begin{array}{l}\uparrow \text { oxidative stress and inflammation } \\
\uparrow \text { mesangial cell proliferation inhibition, hypertrophy, and apoptosis } \\
\uparrow \text { podocyte damage, glomerular hypertrophy, and proteinuria } \\
\uparrow \text { fibrosis } \\
=\text { renal failure and end-stage renal disease } e^{65-75}\end{array}$ \\
\hline Obesity & $\begin{array}{l}\text { RAGE } \equiv \text { HMGB1 and S100 } \\
\uparrow H M G B 1 \text { and S100 } \\
\uparrow J N K, \text { IKK, NF-KB, TNF- } a \\
\uparrow \text { disruption of the hypothalamic function }\end{array}$ & $\begin{array}{l}\uparrow \text { oxidative stress and inflammation } \\
\uparrow \text { body weight and energy intake } \\
\uparrow \text { hypothalamic insulin and leptin resistance } \\
=\text { hypothalamic dysfunction }^{76-78}\end{array}$ \\
\hline Osteoporosis & $\begin{array}{l}\text { RAGE } \equiv \text { HMGB1 and S100 } \\
\uparrow \text { ROS, NF-KB, MAPK, ERK1/2, TNF-a, IL-1 } \beta, \\
\text { caspase-3, Wnt, PI3K, VEGF, MMP-13 }\end{array}$ & $\begin{array}{l}\downarrow \text { mass and structural composition of bone } \\
\downarrow \text { osteoblast growth, differentiation, and apoptosis } \\
\uparrow \text { osteoclast generation }\end{array}$ \\
\hline Cancer & $\begin{array}{l}\text { RAGE } \equiv \text { HMGB1 and S100 } \\
\uparrow \text { extracellular matrix glycation } \\
\uparrow \text { NF-KB, NADPH oxidase, VEGF, local hypoxia } \\
\uparrow \text { tumor-associated macrophages }\end{array}$ & $\begin{array}{l}\uparrow \text { oxidative stress and inflammation } \\
\uparrow \text { epithelial-mesenchymal cell transition and migration } \\
\uparrow \text { cancer microenvironment as well as tumoral angiogenesis and } \\
\text { proliferation } \\
\uparrow \text { cancer initiation, progression, migration, invasion, and } \\
\text { metastasis }{ }^{31,32,86-94}\end{array}$ \\
\hline $\begin{array}{l}\text { Gut microbiome-associated } \\
\text { diseases }\end{array}$ & $\begin{array}{l}\uparrow \text { particular microbiome growth } \\
\uparrow \text { modulation of the composition and } \\
\text { amounts of intestinal microflora } \\
\uparrow \text { proinflammatory cytokines, toxic } \\
\text { metabolites, and bacterial products }\end{array}$ & $\begin{array}{l}\uparrow \text { loss of microbial diversity } \\
\uparrow \text { intestinal epithelial cell damage, gut barrier dysfunction, intestinal } \\
\text { permeability, and bacterial translocation } \\
=\text { systemic endotoxemia, inflammation and multiorgan injury }{ }^{95-101}\end{array}$ \\
\hline Neurodegenerative diseases & $\begin{array}{l}\uparrow \text { reactive gliosis } \\
\uparrow N F-K B\end{array}$ & $\begin{array}{l}\uparrow \text { oxidative stress and cellular stress } \\
\uparrow \text { activated gliosis } \\
=\text { neuronal death and degeneration } n^{4,102-108}\end{array}$ \\
\hline - Alzheimer's disease & $\begin{array}{l}\text { RAGE } \equiv A \beta \text { and HMGB1, AGE- albumin } \\
\downarrow \text { SIRT1 } \\
\uparrow A \beta \text {, tau, and amyloid precursor } \\
\text { protein (APP) } \\
\uparrow \text { phosphorylated tau } \\
\uparrow \text { cross-linked AGE-A } \beta \text { and their aggregates } \\
\uparrow \text { AGE-albumin adducts } \\
\uparrow \text { NF-KB, JNK, ERK1/2, caspase-3, PI3K, Bax, } \\
\text { iNOS, p38, JAK/STAT }\end{array}$ & $\begin{array}{l}\uparrow \text { oxidative stress } \\
\uparrow A \beta \text { aggregation } \\
\uparrow \text { activated gliosis } \\
=\text { neuronal apoptosis and neurodegeneration } \\
\end{array}$ \\
\hline
\end{tabular}


Table 1 continued

\begin{tabular}{|c|c|c|}
\hline Diseases & Mechanisms & Consequences \\
\hline - Parkinson's disease & $\begin{array}{l}\text { AGEs } \equiv a-s y n u c l e i n \\
R A G E \equiv S 100 \\
\uparrow N F-K B \text { and TNF-a }\end{array}$ & $\begin{array}{l}\uparrow \text { aggregation of a-synuclein toxic oligomers } \\
\uparrow \text { Lewy body formation } \\
\uparrow \text { activated gliosis } \\
\uparrow \text { death of the dopaminergic neurons } \\
=\text { neurodegeneration }^{114-119}\end{array}$ \\
\hline Liver diseases & $\begin{array}{l}\downarrow \text { GSH, SIRT1, and TIMP3 } \\
\uparrow \text { ROS, NF-KB, NADPH oxidase, MAPK } \\
\uparrow \text { phosphorylation of IRS-1, JNK, c-JUN, IKK, } \\
\quad \text { UCP-2, ERK1/2 }\end{array}$ & $\begin{array}{l}\uparrow \text { oxidative stress and inflammation } \\
\uparrow \text { inflammatory cell death of parenchymal cells and tissue remodeling } \\
\text { process fibrosis/cirrhosis } \\
\uparrow \text { cell apoptosis, hepatocyte dysfunction, and steatosis } \\
=\text { induce initiation and progression of NAFLD } \\
=\text { Inflammatory liver injury [nonalcoholic steatohepatitis (NASH)], } \\
\quad \text { hepatic fibrosis and cirrhosis }{ }^{55-57,120-131}\end{array}$ \\
\hline
\end{tabular}

$\uparrow$ increase/activate, $\downarrow$ decrease/inactivate, $=$ lead to/result in, $\equiv$ interact/cross-link.

antiserum can prevent the toxicity induced by AGEs in diabetic microvascular complications ${ }^{57}$.

\section{AGEs and cardiovascular diseases}

AGEs can stimulate cardiovascular complications in the presence or absence of hyperglycemia ${ }^{58}$. The accumulation and exposure to AGEs exacerbate oxidative stress and inflammation and initiate the oxidation of lowdensity lipoproteins (LDLs), which are harmful to cardiovascular function. In blood vessels, accumulated AGEs also interact with mononuclear, endothelial, and smooth muscle cells, resulting in cellular dysfunction, tissue damage, and atherosclerosis development ${ }^{55-57,59}$. In acute myocardial infarction, increased expression of RAGE and its interaction with AGEs, HMGB1, and S100 induce cardiomyocyte apoptosis by activating the MAPK pathway $^{60,61}$. Additionally, higher levels of circulating AGEs are positively correlated with the incidence of cardiovascular disorders and severity of coronary atherosclerosis and coronary artery disease independent of diabetic status $^{62-64}$, suggesting a causal role of AGEs in cardiovascular diseases.

\section{AGEs and kidney diseases}

The kidney is a highly specialized organ that reabsorbs many essential molecules, including water and salt, while removing potentially toxic compounds to protect the body. The accumulation of AGEs in the kidney can elevate oxidative stress and inflammation, contributing to renal failure ${ }^{65}$. In humans, serum contains AGE peptides and free AGE adducts. AGE peptides are generally filtered by renal glomeruli and further reabsorbed by proximal convoluted tubules and eliminated from the body in the form of free AGE adducts in the urine ${ }^{66,67}$. Increased circulating AGEs can accumulate in the renal glomeruli and enhance collagen and laminin production in the extracellular matrix together with proximal tubular senescence, oxidative stress, and inflammatory processes $^{66}$. On the other hand, acute/chronic kidney disease and end-stage renal failure can reduce AGE clearance. Consequently, glomerular and tubular cells are exposed to potentially harmful AGEs for extended periods of time owing to the lower rates of glomerular filtration. These changes lead to accelerated progression and/or exacerbation of kidney malfunction and nephropathy along with greater amounts of AGEs in the circulation ${ }^{68,69}$.

In addition, AGEs can be produced in renal mesangial cells and induce the expression of monocyte chemoattractant protein-1 (MCP-1). AGEs also activate NF- $\mathrm{KB}$, MAPK, and protein kinase $C$ (PKC) to promote mesangial proliferative inhibition, hypertrophy, and apoptosis ${ }^{70,71}$. Similarly, the AGE-RAGE interaction in the kidney can increase oxidative stress, inflammation, and fibrosis by stimulating connective tissue growth factor (CTGF), transforming growth factor- $\beta$ (TGF- $\beta$ ), MAPK, NF- $\mathrm{B}$ and PKC pathways to develop podocyte damage, glomerular hypertrophy, proteinuria, and ultimately endstage renal failure ${ }^{66,72,73}$. The RAGE ligand HMGB1 also plays a causal role in renal inflammation by enhancing ERK1/2, TNF- $\alpha$, interleukin (IL)-6, and MCP-1, leading to nephropathy and chronic kidney disease ${ }^{74,75}$.

\section{AGEs and obesity}

Dietary and endogenous AGEs and the AGE-RAGE interaction can promote oxidative stress and inflammation, contributing to the accelerated progression of obesity-related complications such as elevated serum AGEs, insulin resistance, AGE accumulation, and elevated proinflammatory cytokines in adipose tissues $^{67,76}$, although consumption of dietary AGEs does not 
necessarily increase obesity based on its marginal association with increased body weight gain ${ }^{67,76}$. Adipose tissues also produce molecular RAGE ligands (such as HMGB-1) and RAGE-inducible molecules (e.g., MCP-1 and IL-6). Upon RAGE interaction, these bound molecules activate their own production in adipose tissues, suggesting a causal role of RAGE signaling in the inflammatory pathway ${ }^{49,67}$. In addition to dietary AGEs, endogenous AGEs can be trapped and accumulated in adipose tissues, and AGE accumulation can be prevented by RAGE inhibition ${ }^{77}$.

AGEs are reported to modify energy balance by disrupting hypothalamic function. Aggregated AGEs can activate the JNK, Iк-B kinase (IKK), NF- $\mathrm{kB}$, and TNF- $\alpha$ pathways to trigger hypothalamic insulin and leptin resistance, resulting in hypothalamic dysfunction, imbalanced energy control, and subsequently elevated food consumption and body weight with obesity and metabolic syndromes $^{78}$.

\section{AGEs and osteoporosis}

Body bone mass is determined by the delicate balance between osteoclasts and osteoblasts involved in regulating bone formation, differentiation, and apoptosis in response to various stimuli ${ }^{79}$. In bone, accumulated AGEs can increase osteoclast generation while decreasing osteoblast growth and differentiation. Initially, AGEs enhance the levels of osterix, a transcription factor that promotes osteoblast differentiation and bone formation. However, chronic AGE accumulation induces osteoblast apoptosis through activation of proapoptotic caspase-3, MAPK, and intracellular ROS generation ${ }^{80-82}$, indicating an intricate role for AGEs in bone physiology and remodeling.

The interaction of AGE-RAGE augments the production of proinflammatory cytokines and suppresses osteoblast differentiation via the Wnt, PI3K, and ERK1/ 2 signaling pathways ${ }^{83}$. Moreover, RAGE binding to its ligands (such as HMGB1 and S100) also triggers the production or activation of TNF- $\alpha$, IL-1 $\beta$, caspase-3, MAPK, NF-kB, vascular endothelial growth factor (VEGF), and matrix metalloproteinase 13 (MMP-13), negatively affecting the mass and structural composition of bone ${ }^{84}$. Notably, several conditions, including aging, diabetes, renal failure, tobacco smoking, and excessive alcohol consumption that induce AGE accumulation and AGE-RAGE interaction, are risk factors for increased bone fracture and osteoporosis ${ }^{46,85}$.

\section{AGEs and cancer}

Elevated amounts of AGEs are observed in tumor tissues in cancer. Increased AGEs and AGE-RAGE interactions provide a link to cancer initiation, progression, migration, and metastasis ${ }^{31,86}$. The binding of AGEs to RAGE triggers extracellular matrix glycation, NADPH oxidase activity, local hypoxia, VEGF expression, and NF$\kappa \mathrm{B}$ activation to produce oxidative stress and inflammation, supporting the cancer microenvironment and promoting tumoral angiogenesis and proliferation ${ }^{32,87}$.

The overexpression of RAGE and its interaction with a ligand are associated with various types of cancer. RAGE is highly upregulated in metastatic and aggressive breast, ovarian, and pancreatic cancer, acting as a promotor of the progression of premalignant precursors to invasive carcinoma $^{88,89}$. In hepatocellular carcinoma (HCC), RAGE overexpression and interaction with HMGB1 induce tumor-associated macrophage activation and NF$\kappa \mathrm{B}$ expression to promote tumoral proliferation, invasion, and metastasis ${ }^{90,91}$. After binding with S100, RAGE also contributes to the epithelial-mesenchymal cell transition and cell migration, which is associated with tumor invasion and metastasis in cervical cancer and osteosarcomas, suggesting a contributing role for RAGE in tumor malignancy ${ }^{92}$. Furthermore, in cigarette smokers, elevated levels of RAGE are positively correlated with the development of oral squamous cell, lung, and breast carcinoma $^{93,94}$.

\section{AGEs and gut microbiome-associated diseases}

The gut microbiota plays a critical role in regulating body function by producing diverse metabolites and influencing the gut-liver-brain axis and other pathways, such as immune system pathways. The composition and function of gut flora can be affected by endogenous and exogenous factors, particularly food consumption with different levels of dietary AGEs ${ }^{95,96}$.

In the body, less than 30\% of dietary AGEs are absorbed in the intestine after ingestion, and less than 15\% are excreted in urine and feces, leading to a hypothesis that the remaining unabsorbed AGEs are degraded by gut microorganisms ${ }^{97}$. The intestinal microbiota produces deglycating enzymes to digest AGEs, which are utilized for energy production. As a result of this mechanism, unabsorbed AGEs may play a role in modulating the composition and number of intestinal microflora ${ }^{98}$.

AGEs can modify gut microbiota composition by triggering the growth of particular microbiomes, resulting in the loss of microbial diversity and an increased possibility of intestinal leakiness ${ }^{98,99}$. Elevated accumulation of AGEs can enhance gut barrier dysfunction, intestinal permeability, and bacterial translocation by stimulating the production and release of proinflammatory cytokines, potentially toxic metabolites and bacterial products, as well as causing intestinal epithelial cell damage, contributing to systemic endotoxemia, inflammation, and multiorgan injury ${ }^{98}$. AGE-modulated gut microflora is also associated with the pathogenesis of type $2 \mathrm{DM}$, obesity, neurodegenerative diseases such as $\mathrm{AD}$, and endstage renal failure, where restriction of dietary AGEs can 
improve the gut microbial composition and subsequently attenuate disease conditions ${ }^{100,101}$.

\section{AGEs and neurodegenerative diseases}

The brain is a highly specialized organ with tightly regulated motor, behavior, neurocognitive, and executive functions. However, it generally lacks defensive or protective enzymes/proteins compared to peripheral tissues such as the liver and kidney ${ }^{102}$. Thus, under normal conditions, the brain is protected by a special functional system, the blood-brain barrier (BBB). In the brain, AGEs can be produced as a result of elevated oxidative stress during aging or chronic exposure to toxic agents such as alcohol (ethanol), n-6 fatty acid-containing high-fat Western diets, and sugary soft drinks. Oxidative stress can also be generated due to AGE formation in the brain. This feed-forward process creates a vicious cycle that exacerbates oxidative damage with the subsequent initiation and progression of neurodegenerative diseases ${ }^{4,103}$. However, the amounts of plasma AGEs, which can stimulate the aggregation of specifically modified proteins, are different in Alzheimer's and Parkinson's disease patients in a sexdependent manner, thus requiring a careful interpretation of test results ${ }^{104}$. Similar to AGEs, RAGEs are significantly or markedly expressed in many areas of the brain, such as the cortex, hippocampus, cerebellum, and substantia nigra $^{105-107}$ during the development of neurodegenerative diseases. Activated microglial cells produce and secrete AGE-albumin to induce RAGE expression in neurons and promote neuronal cell death, thereby contributing to neurodegenerative disorders ${ }^{4,108}$. Additionally, the accumulation of AGEs and the AGE-RAGE interaction greatly induce reactive gliosis and the NF- $\mathrm{kB}$ proinflammatory pathway, leading to cellular stress, activated gliosis, and eventually neuronal degeneration ${ }^{105}$.

\section{AGEs and Alzheimer's disease}

Various forms of AGEs are markedly aggregated in neuronal plaques in the brain as well as in the serum and cerebrospinal fluid (CSF) in experimental models and autopsied brains from $\mathrm{AD}$ patients compared with the corresponding controls. Accumulated AGEs can accelerate the formation of $A \beta$, tau, and amyloid precursor protein (APP) and induce the hyperphosphorylation of tau and the cross-linking of AGE-A $\beta$, leading to an increase in these aggregates ${ }^{109}$. AGEs also suppress SIRT1 expression and stimulate inducible nitric oxide synthase (iNOS) and caspase-3 to enhance neuronal apoptosis and/ or degeneration with elevated gliosis ${ }^{110}$.

One of the most abundant AGE-protein adducts in the brain is the AGE-albumin adduct, which was confirmed by mass spectral analysis, and causes RAGE overexpression in primary neurons in human AD brains. The formation of the AGE-albumin adduct is intensified by elevated oxidative stress and $A \beta$ aggregation ${ }^{111} . A \beta$ is also produced by the AGE-albumin-RAGE interaction, which in turn supports AGE-albumin adduct formation in a positive feed-forward cycle. The binding of the AGEalbumin adduct to RAGE provides a link to neuronal apoptosis by activating the proapoptotic JNK and Bcl-2associated $\mathrm{X}$ protein (Bax) pathways ${ }^{111}$. In addition to AGEs and AGE adducts, HMGB1 and $A \beta$ can bind RAGEs to activate the NF-kB, ERK1/2, p38, JNK, PI3K, Janus kinase/signal transducers and activators of transcription (JAK/STAT) pathways, leading to neuronal cell death and neurodegeneration ${ }^{112}$. Furthermore, AGEs cross-linked with $A \beta$ can also decrease the ability of microglia to clear plaques ${ }^{113}$.

\section{AGEs and Parkinson's disease}

Dietary AGEs promote AGE formation in the substantia nigra $^{114}$. In PD brains, AGEs can accumulate early in newly formed Lewy bodies, suggesting that AGEs could play a contributing role in Lewy body formation in developing $\mathrm{PD}^{115}$. AGEs cross-linked with $\alpha$-synuclein are also present in PD brains, resulting in the aggregation of $\alpha$-synuclein toxic oligomers ${ }^{115,116}$. Moreover, RAGE can interact with S100 in PD brains, activating the NF- $k B$ and TNF- $\alpha$ signaling pathways to promote dopaminergic neuronal death and subsequent neurodegeneration in $\mathrm{PD}^{117,118}$. AGE-albumin, the most abundant AGE product in the human PD brain, is synthesized by activated microglial cells. Aggregated AGE-albumin upregulates RAGE, leading to the apoptosis of primary dopamine neurons in the brain ${ }^{119}$.

\section{AGEs and liver diseases}

The liver plays a vital role in the metabolism and synthesis of various essential molecules and proteins needed for many other organs. It is involved in the catabolism and elimination of circulating AGEs using liver sinusoidal endothelial cells and Kupffer cells. This function of the liver declines during the aging process and in various liver diseases, resulting in the accumulation of AGEs or their aggregates ${ }^{120,121}$.

Intracellular AGE accumulation is observed in animal models of hepatic steatosis and other advanced liver diseases, such as hepatic inflammation (steatohepatitis) and fibrosis/cirrhosis. Accumulated AGEs in hepatocytes can stimulate apoptosis and inflammation, leading to cellular dysfunction, steatosis, and ultimately nonalcoholic fatty liver disease (NAFLD) ${ }^{121-123}$.

Endogenous and exogenous AGEs provoke the initiation and progression of NAFLD. However, consumption of dietary AGEs from sources such as fructose- or sucrose-enriched diets and/or soft drinks can worsen liver fibrosis faster than consumption of endogenous AGEs. The aggregation of AGEs decreases the levels of the most 
important cellular antioxidant peptides, glutathione (GSH), SIRT1, and tissue inhibitor of metalloproteinase 3 (TIMP3), accompanied by increased oxidative stress and inflammation, promoting inflammatory liver injury and fibrosis in experimental animal models and NAFLD patients $^{55-57,124-126}$.

Accumulated AGEs and AGE-RAGE interactions in these cells augment the generation of ROS and the activation of MAPK and NF- $\mathrm{kB}$ pathways, leading to inflammatory cell death in the parenchyma and tissue remodeling processes during fibrosis ${ }^{127,128}$.

Increased amounts of RAGE are also observed in the liver of hepatocellular carcinoma (HCC), and its level is significantly greater than it is liver affected by hepatitis and healthy liver specimens. The amounts of serum AGEs are also higher in HCC than in NASH and healthy liver specimens. In HCC, the AGE-RAGE interaction is associated with angiogenesis and tumor proliferation and invasion, which are ameliorated by RAGE inhibition. These results suggest an important role for AGEs and RAGE in promoting NAFLD, NASH, fibrosis/cirrhosis, and HCC pathogenesis ${ }^{129-131}$.

\section{AGEs and alcohol-mediated tissue injury \\ Alcohol metabolism (see summary in Fig. 1) Hepatic alcohol metabolism}

The major type of alcohol that is consumed is ethanol $\left(\mathrm{CH}_{3} \mathrm{CH}_{2} \mathrm{OH}\right)$. Upon consumption, ethanol is absorbed via simple diffusion in the small intestine into the blood and rapidly circulates throughout the body ${ }^{6}$. Ethanol metabolism primarily occurs in the liver in three major steps: (1) ethanol oxidation to acetaldehyde, (2) acetaldehyde metabolism to acetate, and (3) acetate catabolism to $\mathrm{H}_{2} \mathrm{O}$ and $\mathrm{CO}_{2}{ }^{132-134}$.

In step I of the hepatic oxidative metabolism of alcohol (ethanol), three distinct enzymes are involved: alcohol dehydrogenase $(\mathrm{ADH})$, catalase, and cytochrome P4502E1 (CYP2E1). Cytosolic ADH is a major enzyme that catalyzes the oxidative metabolism of ethanol to acetaldehyde by using the cofactor nicotinamide adenine dinucleotide $\left(\mathrm{NAD}^{+}\right)$converted to $\mathrm{NADH}^{132-134}$. Catalase present in peroxisomes may participate in ethanol oxidation in the presence of $\mathrm{H}_{2} \mathrm{O}_{2}{ }^{132-134}$, although this enzyme appears to play no major role in hepatic ethanol metabolism under physiological conditions due to the limited supply of $\mathrm{H}_{2} \mathrm{O}_{2}{ }^{135}$. After chronic and/or large amounts of ethanol intake, CYP2E1, the major component of the microsomal ethanol oxidizing system (MEOS) with a higher $\mathrm{km}(\sim 10 \mathrm{mM}$ for ethanol) than that of ADH $(\mathrm{km}<1 \mathrm{mM}$ for ethanol), is also involved in ethanol metabolism through an NADPH-dependent pathway. In contrast to those of ADH and catalase, CYP2E1 expression and activity are usually induced by ethanol and other substances, such as dietary fats. The induction and activation of CYP2E1, in turn, contribute to alcohol- and nonalcohol-induced pathophysiology ${ }^{136-144}$. In the second step, acetaldehyde is converted to acetate due to the low $\mathrm{km}$ (for acetaldehyde) mitochondrial aldehyde dehydrogenase 2 isozyme (ALDH2) in humans ${ }^{145}$. Notably, CYP2E1 also takes part in this step with NADPH acting as a cofactor to convert acetaldehyde to acetate ${ }^{146}$. Finally, the acetate that is produced is further degraded to $\mathrm{CO}_{2}$ and $\mathrm{H}_{2} \mathrm{O}$, ending the final step of ethanol oxidation in the liver ${ }^{132-134}$. Furthermore, the remaining unmetabolized ethanol, acetaldehyde, and acetate can be distributed to many other organs, including the heart, lung, kidney, pancreas, and brain, causing damage in various peripheral tissues and neurobehavioral effects caused by damage to the brain.

\section{Brain alcohol metabolism}

Similar to the liver, ethanol oxidizing enzymes are also functional in the brain and include $\mathrm{ADH}$, catalase, CYP2E1, and ALDH2, which make different contributions. Cerebral ADH plays very little or virtually no role in ethanol metabolism in the brain compared to its action by its hepatic isoform. However, cerebral catalase acts as the main oxidizing enzyme, accounting for more than $60 \%$ of ethanol oxidation in the brain under normal conditions ${ }^{147}$. However, catalase may have a limited role in ethanol metabolism in certain brain regions, except for aminergic neurons, where it is present in high concentrations $^{134,148-150}$. In contrast, CYP2E1 is widely expressed throughout the brain, such as in the cerebral cortex, hippocampus, and cerebellum. Similar to that in the liver, brain CYP2E1 is also inducible by ethanol and may therefore play a key role in cerebral ethanol metabolism, especially after chronic and/or binge alcohol intake $^{151-155}$. The role of CYP2E1 in brain ethanol metabolism and its association with alcohol-mediated oxidative neuronal injury ${ }^{155-160}$ and aging-related $\mathrm{AD}$ and $\mathrm{PD}^{161}$ have also been suggested. Finally, mitochondrial ALDH2 is the final enzyme for converting acetaldehyde to acetate $^{148}$, although acetaldehyde is locally produced in the brain due to its very limited ability to cross the $\mathrm{BBB}^{162}$. In contrast, ALDH1B and other isoforms may be involved in acetaldehyde metabolism in rodents ${ }^{145,147,163}$.

\section{AGE-alcohol-adduct formations (Fig. 1)}

Free amino acid residues of proteins, lipids, nucleic acids, and nucleophilic molecules are major targets of adduct formation or covalent binding with reactive molecules such as acetaldehyde, acrolein, crotonaldehyde, formaldehyde, malondialdehyde, 4-hydroxynonenal, 8-hydroxydeoxyguanosine, N2-((furan-2-yl)methyl)-2'deoxyguanosine, and $\mathrm{N}^{2}$-ethyl-2'-deoxyguanosine ${ }^{164-166}$. After alcohol consumption, CYP2E1 in step I of oxidative ethanol metabolism can generate a series of oxygen free 


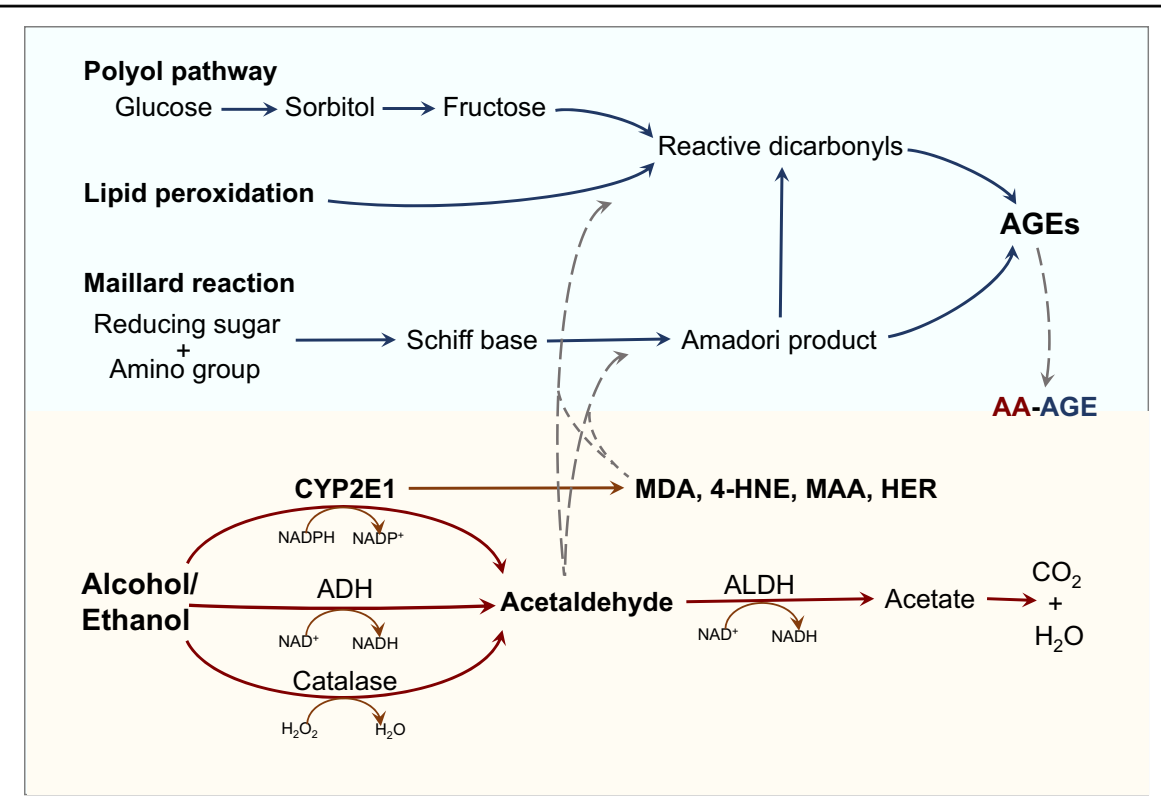

Fig. 1 Overview of the biological connections in AGE-alcohol-adduct formations. Under conditions that increase lipid peroxidation, polyol pathway, and Maillard reaction, such as exposure to alcohol and/or high n-6 fat diets or high fructose drinks, different AGEs are produced. Ethanol and its reactive metabolites generated by CYP2E1 are also likely involved in the AGE synthesis pathways to produce the final acetaldehyde and AGE (AA-AGE) adducts. The formation of AA-AGE adducts can be observed after chronic alcohol exposure. These AA-AGE adducts exhibit similar properties (e.g., brown color and polymerization) as the AGE adducts cross-link with sugar molecules, and they are different from MAA adducts formed by AA and MDA interactions. However, treatment with an antioxidant can halt AA-AGE adduct formation, supporting the idea that AA-AGE adducts can be generated from a Schiff base product similar to AA adducts and AGEs.

radicals (e.g., ROS) to trigger lipid peroxidation, resulting in the formation of various ethanol metabolites and adducts, including (1) acetaldehyde (AA) from ethanol oxidation, (2) malondialdehyde (MDA) and (3) 4hydroxynonenal (4-HNE) from lipid peroxidation, (4) malondialdehyde-acetaldehyde adduct (MAA) from the acetaldehyde-MDA-protein hybrid adduct, and (5) hydroxyethyl radicals (HER) from the presence of iron during ethanol metabolism ${ }^{167-171}$, although some of these adducts may not be readily detected due to their low levels under physiological conditions.

MDA and 4-HNE are reactive lipid peroxides with short half-lives that can form covalent adducts with various proteins and nucleic acids in the body. For instance, ethanol intake can induce 4-HNE to interact with cytochrome $\mathrm{C}$ oxidase (complex IV) and ALDH2 in the mitochondria, GRP78 and disulfide isomerase in the ER, and ERK1/2, phosphatase and tensin homolog (PTEN), AMP-activated protein kinase (AMPK), and gammaglutamylcysteine synthetase (GCS) in the cytosol. These adduct formations inactivate their target proteins and result in the accumulation of lipid aldehydes, ER stress, mitochondrial dysfunction, cell signaling alteration, and potentially multitissue injury ${ }^{172-177}$.

Interactions between acetaldehyde or MDA and cellular proteins lead to the formation of MAA adducts, which are highly stable and resistant to rapid degradation ${ }^{178,179}$.
Increased levels of MAA adducts from alcohol exposure stimulate protein dysfunction and immune-induced tissue injury through interactions with Toll-like receptor-3 (TLR-3), TLR-6, calpain, collagen alpha-1 (XII) chain, procollagen type XIV alpha-1, protocadherin beta, or complement component proteins ${ }^{167,180}$.

Acetaldehyde adducts (AA adducts) are formed by the interaction of acetaldehyde, a direct metabolite of ethanol oxidation and a human carcinogen, with certain amino acids, including lysine, cysteine, and aromatic amino acids. However, these amino acids in different proteins may exert an unequal preference for AA adduct formation. The proteins commonly bound to acetaldehyde to produce AA adducts include membrane proteins of the red blood cells (erythrocytes), hemoglobin (oxygen transport), tubulin (cellular structure), lipoproteins (lipid transport), albumin (blood), and collagen (connective tissue ${ }^{167,169,180}$. In addition, some of these AA adducts are produced in a CYP2E1-dependent manner ${ }^{137,181}$.

The formation of adduct proteins can prolong protein half-lives and accumulate as aggregated proteins. Since mammalian ubiquitin-dependent proteasomal degradation is usually catalyzed after the conjugation of ubiquitin with lysine residues, it is expected that AA adduct formation and ubiquitin conjugation may compete for common lysine residues. Therefore, when lysine residues are already occupied by reactive acetaldehyde, lipid 
Table 2 Summary of the biological connections of AGE-alcohol-adducts with alcohol-mediated tissue injury.

\begin{tabular}{|c|c|c|}
\hline Cells/organs & AGE-alcohol-adducts & Consequences \\
\hline \multirow[t]{17}{*}{ Brain } & AGE-albumin adducts & $\uparrow$ RAGE overexpression \\
\hline & & $\uparrow$ MAPK (JNK and p38K), Bax, and microglial activation \\
\hline & & $\uparrow$ neuronal inflammation, apoptosis, and damage ${ }^{108,111,119,202}$ \\
\hline & Ethanol & $\uparrow$ RAGE expression \\
\hline & & $\uparrow$ ROS, Nrf2, GFAP, Iba1, lipid peroxidation, HMGB1, \\
\hline & & TLR-4, neuroimmune markers, \\
\hline & & $\uparrow$ CYP2E1, oxidative stress, and inflammation \\
\hline & & $\uparrow$ neuroinflammation, neuronal apoptosis, and memory Impairment ${ }^{203,204}$ \\
\hline & AA-protein adducts: & $\downarrow$ microtubule formation \\
\hline & AA-tubulin adducts & $\uparrow$ dysfunction of cytoskeletal components of nerve cells \\
\hline & AA-DA adducts (salsolinol) & $\begin{array}{l}\uparrow \text { neurotoxin involved in the pathogenesis of AUD and PD } \\
\uparrow \text { neuronal damage and degeneration }{ }^{189-198}\end{array}$ \\
\hline & AA-DNA adducts & $\downarrow$ DNA integrity and neuronal viability \\
\hline & & $\downarrow$ represses DNA repair enzymes/system \\
\hline & & $\uparrow$ genetic instability and DNA mutations \\
\hline & & $\uparrow$ correlated with AUD $53,192,197,198$ \\
\hline & AA-AGE adducts & $\uparrow$ ROS and oxidative stress \\
\hline & & $\uparrow$ neurotoxicity, neuronal apoptosis, and degeneration in a dose-dependent manner ${ }^{199}$ \\
\hline \multirow[t]{15}{*}{ Liver } & AGE production & $\downarrow$ decrease in albumin turnover in plasma \\
\hline & plasma AGEs & $\uparrow$ aggregation of adduct proteins \\
\hline & AGE-protein adducts & $\uparrow$ activation of Kupffer and HSCS \\
\hline & & $\uparrow$ death of hepatocytes ${ }^{232,233}$ \\
\hline & AA adducts & $\uparrow$ TNF-a, IL-12, IL-18, MIF, PDGF \\
\hline & MDA adducts & $\uparrow$ stimulate the transformation of the HSCs \\
\hline & MAA adducts & $\uparrow$ activate myofibroblasts \\
\hline & 4-HNE adducts & $\uparrow$ activates infiltration of neutrophils into the liver $\downarrow$ ALDH2 function $214-230$ \\
\hline & HER adducts & $\uparrow$ CYP2E1, oxidative stress, AFLD, and advanced ALD $203-213$ \\
\hline & Ethanol & \\
\hline & AA-AGE adducts & $\uparrow$ RAGE expression \\
\hline & & $\uparrow$ ROS and oxidative stress \\
\hline & & $\uparrow$ hepatic fatty degeneration and steatosis \\
\hline & & $\uparrow$ hepatocyte ballooning, apoptosis, and steatosis \\
\hline & & $\uparrow \mathrm{ALD}$ and $\mathrm{AFLD}{ }^{215,231}$ \\
\hline \multirow[t]{8}{*}{ Lung } & soluble RAGE (+HMGB1) & $\uparrow$ lung inflammation ${ }^{239,240}$ \\
\hline & MDA adducts & $\uparrow$ oxidative stress \\
\hline & 4-HNE adducts & $\uparrow$ pulmonary dysfunction \\
\hline & & $\uparrow$ lung epithelial barrier dysfunction \\
\hline & & $\uparrow$ acute respiratory distress syndrome (ARDS) ${ }^{164,234}$ \\
\hline & MAA adducts & $\downarrow$ impedes the wound healing process \\
\hline & & $\uparrow$ inflammatory processes, PKC-mediated release of IL-8 \\
\hline & & $\uparrow$ correlated with AUD ${ }^{179,235-238}$ \\
\hline \multirow[t]{3}{*}{ Heart } & MDA adducts & $\downarrow \mathrm{ALDH} 2$ function \\
\hline & 4-HNE adducts & $\uparrow$ oxidative stress \\
\hline & & $\uparrow$ cardiac dysfunction $^{241-244}$ \\
\hline \multirow[t]{2}{*}{ Gut } & AA-adducts & $\uparrow$ oxidative stress \\
\hline & AA-MDA adducts & $\uparrow$ leaky gut with increased intestinal cell permeability and endotoxemia $137,181,245-250$ \\
\hline
\end{tabular}


Table 2 continued

\begin{tabular}{lll}
\hline Cells/organs & AGE-alcohol-adducts & Consequences \\
\hline Pancreas & 4-HNE adducts & $\uparrow$ pancreatitis, $\beta$-cell apoptosis ${ }^{251-255}$ \\
& HER adducts & \\
Erythrocytes & AA adducts & $\uparrow$ correlated with FASD \\
Testis & RAGE overexpression & $\uparrow$ oxidative stress and inflammation $\uparrow$ testis dysfunction and degeneration ${ }^{253,259-261}$ \\
\hline
\end{tabular}

$\uparrow$ increase/activate, $\downarrow$ decrease/inactivate.

aldehydes, AGEs, or AA, adducts persist for extended periods of time and may end up as aggregated proteins due to the lack of free lysine needed for ubiquitin conjugation and subsequent proteolysis. In fact, the hypothesis of extended half-lives and aggregations of these adduct proteins is exemplified by the stabilization of CYP2E1 by ethanol and acetone through the blockade of its rapid degradation via ubiquitin-dependent proteolysis $^{182-186}$.

AA adducts are produced in two separate pathways that yield two different types of adducts, depending on the existing conditions. The first pathway is the formation of AA adducts with specific amino acids (lysine, cysteine, or aromatic amino acids) and $N$-ethyl amino acid groups under reducing conditions. The second is AA adduct synthesis under nonreducing conditions, that creates a wide range of adducts for which the complete mechanisms remain to be further characterized. In the second pathway, the initial step is the formation of a Schiff base adduct followed by several rearrangements and reactions to yield diverse AA adducts ${ }^{168}$.

Under conditions that include increased lipid peroxidation, such as exposure to alcohol and/or high n- 6 fat diets or intake of high fructose drinks, different AGEs are produced by Schiff base formation (Fig. 1). Thus, ethanol and its reactive metabolite, acetaldehyde, are likely involved in the AGE synthesis pathways to produce the final acetaldehyde and AGE (AA-AGE) adducts. The formation of AA-AGE adducts can be observed after chronic alcohol exposure. These AA-AGE adducts exhibit similar properties (e.g., brown color and polymerization) as the AGE adducts cross-link with sugar molecules, and they are distinguished from MAA adducts formed by AA and MDA interactions. Furthermore, treatment with an antioxidant can halt AA-AGE adduct formation, supporting the idea that AA-AGE adducts can be generated from a Schiff base product similar to AA adducts and AGEs ${ }^{168}$.

\section{Brain (see summary in Table 2)}

Chronic and excessive alcohol consumption can alter brain structure and function, causing behavioral, emotional, and intellectual abnormalities. These neurobehavioral changes include the development of alcohol tolerance and addiction, emotional dysregulation, and executive, neurocognitive, and motor dysfunctions with neuroinflammation and/or neurodegeneration. Excessive alcohol exposure increases oxidative stress and the levels of reactive acetaldehyde and lipid aldehydes with a simultaneous decrease in defensive molecules and detoxification enzymes, including GSH and ALDH2 $2^{53,172,177}$. These changes subsequently lead to the accumulation of acetaldehyde adducts and possibly AGEs in the brain, which has a much lower detoxification capacity than the liver, as previously mentioned ${ }^{102}$. Additionally, reactive electrophilic acetaldehyde can strongly induce covalent adduct formation with nucleophilic molecules such as proteins and DNA, forming acetaldehydeprotein (AA-protein) or acetaldehyde-DNA (AA-DNA) adducts in the brain ${ }^{187-189}$.

AA-protein adducts are widely present in the brains of alcohol-exposed rodents or people with alcohol use disorder (AUD) $)^{189-192}$. After alcohol consumption, AAprotein adducts are rapidly produced in the cerebral cortex primarily with mitochondrial proteins and localized in the white matter, deep layers of the frontal cortex, and molecular layer of the cerebellum ${ }^{188,189,191}$. AAprotein adducts are also formed with cytosolic proteins, including tubulins, known as AA-tubulin adducts, resulting in microtubule malformation and the cytoskeletal dysfunction of nerve cells ${ }^{193,194}$. Furthermore, acetaldehyde can interact with dopamine (DA) to produce AA-DA adducts, including salsolinol, a neurotoxin and potent stimulant in alcohol, which is involved in the pathogenesis of AUD and $\mathrm{PD}^{194,195}$. Additionally, the aggregation of these AA-protein adducts can enhance neuronal damage and degeneration in different brain regions ${ }^{190,196}$. These findings suggest a critical role for AA-protein adducts in promoting brain damage and pathophysiology associated with chronic alcohol consumption.

The presence of acetaldehyde in the brain also alters DNA integrity and neuronal viability. Acetaldehyde can form AA-DNA adducts in the brain and in peripheral blood leukocytes of people with AUD since ethanol, acetaldehyde, and lipid aldehydes such as MDA and 4-HNE can inhibit DNA repair enzymes ${ }^{53}$. The dual 
mechanisms of simultaneously elevated AA-DNA adducts and suppressed DNA repair systems following alcohol intake may contribute to genetic instability and DNA mutations, promoting neurological pathologies ${ }^{192,197,198}$.

In addition to cerebral AA-protein adducts, ethanol intake or exposure can induce and accelerate AGE production in the brain. Aggregation of cross-linked AGEs further upregulates RAGE expression and activation, contributing to diverse outcomes with neurobehavioral impairment, as observed in people with AUD ${ }^{190}$.

In neurons, direct exposure of AA-AGE adducts to cortical neurons triggers ROS generation, leading to oxidative stress and consequently neuronal apoptosis and degeneration in a dose-dependent manner. These effects can be prevented by treatment with the antioxidant $N$ acetylcysteine (NAC) or a neutralizing anti-AA-AGE antibody, suggesting a direct role for AA-AGE adducts in generating oxidative stress-induced neurotoxicity ${ }^{199}$. Daily alcohol exposure for ten consecutive days also instigated microglial activation to synthesize and secrete AGE-albumin adducts in the hippocampus and entorhinal cortex of the rat brain. Accumulated AGE-albumin adducts increase the expression of RAGE and activate the MAPK (JNK and p38K)-dependent cell death pathway to promote inflammation, apoptosis, and neuronal damage, which are significantly attenuated by treatment with soluble RAGE and chemical AGE inhibitors ${ }^{200}$. Moreover, ethanol ingestion also upregulates RAGE expression in the orbitofrontal cortex and increases the levels of oxidative stress, HMGB1, TLR-4, neuroimmune markers, and proinflammatory cytokines in the brain ${ }^{201}$. Additionally, chronic exposure to alcohol enhances RAGE expression, ROS generation, nuclear factor erythroid 2-related factor 2 (Nrf2), TLR-4, glial fibrillary acidic protein (GFAP), ionized calcium-binding adapter molecule 1 (Iba1), and lipid peroxidation, resulting in neuroinflammation, neuronal apoptosis, and memory impairment ${ }^{202}$. These results strongly suggest a contributing role of the AGE-RAGE axis in alcohol-induced neuroinflammation and neurodegeneration through elevated oxidative stress and upregulated cell death pathways in the brain.

\section{Liver}

Chronic and excessive alcohol intake is known to cause liver injury from mild steatosis (simple fat accumulation in so-called alcoholic fatty liver disease, AFLD) to more advanced liver disease such as inflammation (alcoholic steatohepatitis, ASH), fibrosis/cirrhosis, hepatic cancer, liver failure, and death ${ }^{203-213}$. Although many aberrant signaling pathways are found in the pathogenesis of liver diseases, elevated levels of adducts with AA, MDA, MAA, 4-HNE, and HER likely contribute to alcohol-induced cell injury $^{214,215}$. After ethanol intake, AA, MDA, and 4-HNE adducts are produced rapidly in the hepatic centrilobular zone (zone III), sinusoids, and HSCs as well as on the hepatocyte surface in the liver. The amounts of these adducts are also markedly elevated in the early phase of alcoholic liver disease (ALD) in the presence or absence of clinical or histological signs ${ }^{216-219}$, suggesting their role in the initial development and progression of ALD. In addition to individual $\mathrm{AA}$ and MDA adducts, MAA adducts (AA-MDA-protein hybrid adducts) are found in HSCs, liver sinusoidal endothelial cells, and Kupffer cells in ALD models. They also stimulate the transformation of HSCs into activated myofibroblasts, resulting in the elevated production of potent profibrotic factors such as platelet-derived growth factor (PDGF) ${ }^{220-222}$. The presence of MAA adducts in these cells can induce proinflammatory cytokines such as TNF- $\alpha$, IL-12, IL-18, and macrophage migration inhibitory factor $(\mathrm{MIF})^{223-225}$. In hepatic Kupffer cells, 4-HNE adducts are also present and activate the infiltration of neutrophils into the liver, leading to the activation of HSCs and an inflammatory cytokine response ${ }^{226-228}$. These findings indicate a contributing role of MAA and 4-HNE adducts in promoting the hepatic immune response associated with ALD development. In advanced ALD with cirrhosis, 4-HNE and MDA adducts are also found in greater amounts than in nonalcoholic liver cirrhosis and normal liver ${ }^{139,228}$, suggesting the involvement of 4-HNE and MDA adducts in promoting advanced ALD. Finally, adducts derived from HER are also detected in the liver and localized in the microsomes and plasma membranes of hepatocytes and are inducible by alcohol exposure ${ }^{229,230}$.

Ethanol consumption stimulates the formation of AAAGE in the liver. Increased AA-AGE adduct formation and accumulation were positively correlated with the progression of ALD, as indicated by hepatic fat accumulation and steatohepatitis, which are reversibly ameliorated by alcohol abstinence ${ }^{215}$. HSCs directly exposed to AA-AGE adducts can enhance RAGE expression, ROS generation, and oxidative stress to promote hepatocyte ballooning, apoptosis, and steatosis $^{231}$. These findings suggest a role for AA-AGE adducts in the pathogenesis of AFLD. Alcohol ingestion also enhances AGE synthesis and plasma AGEs in the circulation, especially in the portal and hepatic veins of cirrhotic livers. Elevated AGE levels support AGEprotein adduct formation accompanied by decreased albumin turnover in plasma ${ }^{232}$. Additionally, AGEprotein adducts can accumulate as aggregated proteins in the cells, leading to the activation of Kupffer and HSCs in the liver and microglial cells in the brain followed by parenchymal cell death (e.g., hepatocytes and neurons, respectively), suggesting the involvement of AGEs in the progression of ALD and alcohol-mediated multiorgan injury ${ }^{233}$. 


\section{Other organs}

Although more detailed studies need to be conducted, the involvement of AGEs - alcohol -adducts in different cells/tissues is presented as follows:

Lung Chronic and/or excessive alcohol intake can cause acute respiratory distress syndrome (ARDS) and other types of pulmonary dysfunction characterized by reduced air exchange rates with increased lung epithelial barrier dysfunction, possibly through increased oxidative stress and MDA and 4-HNE adducts ${ }^{164,234}$. Ethanol intake stimulates MAA adduct formation in the lung. Elevated levels of MAA adducts are found in the pulmonary bronchoalveolar lavage fluids obtained from chronically alcohol-exposed animals and in people with AUD ${ }^{179,235}$. MAA adducts bind scavenger receptor A (SR-A) on lung macrophages to activate inflammatory processes in airway epithelial cells ${ }^{236}$. The formation of MAA adducts also impedes the wound healing process of bronchial epithelial cells and activates PKC-mediated release of IL-8 in the lung. However, these changes are attenuated by treatment with PKC inhibitors ${ }^{237,238}$. In addition to adduct formation, ethanol exposure can increase soluble RAGE expression in bronchoalveolar lavage fluid together with RAGE ligand (HMGB1) in the inflammatory lung ${ }^{239,240}$.

Heart Excessive alcohol consumption is known to cause cardiac dysfunction with reduced blood ejection force and volume, possibly by augmenting oxidative stress, increasing the levels of MDA and 4-HNE adducts and suppressing ALDH2 activity ${ }^{241,242}$. Elevated oxidative stress caused by alcohol oxidation increases acetaldehyde and MDA adduct synthesis in the heart ${ }^{243,244}$. However, the contributing roles of AA-MDA adducts in alcohol-mediated myocardiopathy need to be further characterized. Since CYP2E1 and ALDH2 are expressed in the heart, future studies of the opposite regulation of CYP2E1 (i.e., induction) and ALDH2 (i.e., suppression) during the alcohol-mediated production of MDA and/or 4-HNE adducts and the consequent cardiomyopathy would be of interest.

Gut Excessive alcohol intake is known to cause leaky gut with increased intestinal cell permeability and endotoxemia, possibly via increased CYP2E1 and oxidative stress $^{245-248}$. Ethanol ingestion is likely to increase AA formation in the intestine as a consequence of gut bacteria-mediated alcohol metabolism and the low levels of ALDH2 expression in the gut ${ }^{249}$, although additional studies are needed to extrapolate the roles of these factors in alcohol-mediated gut damage and inflammation. Since CYP2E1 was shown to be involved in the production of hepatic AA- and AA-MDA adducts ${ }^{137,181,250}$, it would be of interest to study the direct role of CYP2E1 in alcoholmediated AGE production and GI pathologies.
Pancreas Consumption of alcohol enhances the expression of 4-HNE and HER adducts as well as inflammation in the pancreas ${ }^{251,252}$. The functional role of these adducts may be related to alcohol-mediated pancreatitis, although this area needs to be evaluated in the future. Since CYP2E1 and ALDH2 are also expressed in the pancreas $^{253-255}$, future study of the opposite regulation of CYP2E1 (i.e., induction) and ALDH2 (i.e., inactivation) during the production of MDA and/or 4-HNE adducts and the subsequent damage may be important for understanding the pathogenesis mechanisms of alcoholmediated pancreatitis and dysfunction.

Serum Ethanol intake is known to increase the amounts of MDA adducts and AGEs in the serum. The amounts of MDA adducts are more positively correlated with AGE concentrations than with blood glucose levels ${ }^{256}$. However, the effect of elevated MDA adducts in serum on alcohol-related multiorgan damage needs to be investigated in the future.

Erythrocytes After alcohol consumption, AA adducts are produced in blood erythrocytes and are also correlated with the incidence of fetal alcohol spectrum disorders (FASDs $^{257,258}$. The pathological mechanisms and implications of these findings need to be evaluated in future studies.

Testis Excessive alcohol consumption is known to cause testis dysfunction and degeneration, possibly by increasing oxidative stress. Alcohol intake can induce RAGE overexpression in the testis, whereby RAGE is localized in the interstitial cells and the basal compartment of the seminiferous tubules. Prolonged ethanol exposure stimulates RAGE activation to produce oxidative stress and inflammatory mediators, leading to testicular dysfunction and degeneration ${ }^{259}$. CYP2E1 and ALDH2 are also expressed in the testis ${ }^{253,260,261}$. Thus, it would be of interest to find the opposite regulations (i.e., induction of CYP2E1 with suppression of ALDH2) and their implications in alcohol-mediated production of MDA and/or 4HNE adducts and subsequent testis dysfunction.

\section{Translational applications}

We have thus far described the formation of various AGE adducts, interactions with many cellular components, including RAGE, and their pathological implications in aging-related diseases and alcohol-mediated multiorgan damage. Considering the underlying molecular mechanisms of these processes and functional implications, we can suggest a variety of different strategies for use in the effective prevention and therapy of AGEassociated tissue injury and/or RAGE-related diseases. 
For instance, we can reduce the amounts of potentially harmful AGEs by decreasing the production of endogenous AGEs to prevent many disease states, including aging-related diseases, and by lowering the dietary intake of exogenous AGEs. In fact, decreased intake of $n-6$ fatty acids in high-fat Western diets, dairy products, and soft drinks with high fructose or sucrose contents in conjunction with increased consumption of n-3 fatty acidenriched fish and plant-based foods such as legumes, vegetables, fruits, and whole grains are recommended to decrease AGE levels in the body. These healthy dietary choices are consistent with the food recommendations of the American Diabetes Association, the American Heart Association, and the American Institute for Cancer Research $^{262-264}$. Many herbs and spices, such as cloves, rosemary, and curcumin, and natural antioxidants, such rice (Oryza sativa L.), and blueberry, exhibit antiglycation activities. These foods are rich in polyphenols such as gallic acid, flavonoids, anthocyanin, and ferulic acid, which attenuate protein glycation and prevent the biosynthesis of AGEs ${ }^{265-270}$. As mentioned above, cooking methods can play a critical role in regulating the levels of AGE formation, with effects ranging from those caused by oven-frying > frying > broiling > roasting > boiling/ poaching/stewing/steaming. For example, cooking meat (e.g., chicken, pork, or beef) by boiling or stewing can reduce the AGE contents to one-half of that prepared by broiling ${ }^{1,271}$. In addition, the water content, cooking method, temperature and time, and food $\mathrm{pH}$ are crucial to the final amount of AGEs. Marinating food or meat with acidic ingredients such as lemon juice and vinegar can decrease the amounts of dietary AGEs produced during the high-heat cooking process by as much as $50 \%{ }^{272}$. These culinary methods are commonly used for traditional Asian, Mediterranean, and other cuisines worldwide to create palatable and healthy dishes. In addition, changes in behavior or lifestyle, such as decreasing the amount and frequency of alcohol intake and tobacco smoking, and engaging in physical exercise to reduce obesity and diabetes can lower the production of endogenous AGEs, subsequently preventing AGEassociated disease conditions.

We have also described the roles of increased oxidative stress in promoting the production of AA, MDA, MAA, and other AGE-related adducts and the consequences in aging-related diseases and alcohol-mediated multiorgan damage. In particular, CYP2E1 contributes to the production of AA and MAA adducts, as demonstrated in experimental rodent and cell culture models ${ }^{137,180,216,273}$. Therefore, the inhibition of oxidative stress-producing enzymes such as CYP2E $1^{137,181}$ and NADPH oxidase ${ }^{274}$ is an option to prevent the formation of AGE adducts and AGE-associated cellular and/or organ damage. For instance, taking naturally occurring CYP2E1 inhibitors (e.g., diallyl disulfide in garlic ${ }^{273,275}$; phenyl isothiocyanate in cabbage and cruciferous vegetables ${ }^{276}$; ellagic acid in pomegranate ${ }^{247}$; polyunsaturated fatty acids, including docosahexaenoic acid (22:6n-3) $)^{277}$ and indole-3-carbinol in vegetables and fruits ${ }^{278}$; berberine in fruits and vegetables $^{279}$; walnut ${ }^{280}$; curcumin $^{281,282}$; quercetin ${ }^{283}$; and synthetic compounds (chlormethiazole and $\mathrm{YH}-$ $439^{137,284}$ ) can prevent alcohol-induced oxidative stress and the formation of various adducts, including AA adducts $^{137}$ and AA-MAA adducts ${ }^{53,285}$, although the preventive effects of all these dietary compounds on AGEassociated adduct formation have not been specifically evaluated. In addition, dietary AGEs decreased the amounts of $\operatorname{SIRT} 1^{131}$ and other defensive proteins, including peroxisome proliferator -activated receptor- $\gamma$ coactivator $1-\alpha(\mathrm{PGC}-1 \alpha)^{51-53}$ and ALDH2 ${ }^{172}$. Subchronic alcohol intake also decreased the levels of SIRT1 and PGC- $1 \alpha$ and other isoforms ${ }^{286,287}$. Thus, activation of SIRT1 by resveratrol and its synthetic structural derivatives $^{288,289}$ and melatonin ${ }^{290}$ may prevent adduct formation and AGE-associated disease conditions. Furthermore, consumption of anti-inflammatory antioxidants from natural dietary supplements ${ }^{279,281,282,290}$ and/or synthetic origins ${ }^{199}$ can help reduce the incidence and severity of AGE-associated inflammation and related disorders. Furthermore, soluble RAGE ${ }^{119,200}$, inhibitors of the RAGE signaling pathway ${ }^{130,131}$, neutralizing antibodies against RAGE $^{57}$ or AA-AGE adduct ${ }^{199}$, and other AGE-degrading compound(s), such as pyridoxamine and ALT-711 ${ }^{200}$, lipoic acid ${ }^{291}$, synthetic compounds OPB-9195 292 , and nitrothiadiazolo[3,2- $\alpha$ ]pyrimidines ${ }^{293}$, have been reported to decrease AGE adduct formation. Based on these findings, lifestyle changes that include decreased alcohol consumption, reduced tobacco smoking, and avoidance of potentially harmful diets along with increased physical exercise and daily intake of vegetables and fruits, should be actively promoted and undertaken for proper management of the levels of AGE-related adducts to help prevent aging-related diseases and alcohol-mediated organ damage.

\section{Concluding remarks (see overview in Fig. 2)}

AGEs can be produced endogenously and exogenously. The accumulation of AGEs and the interaction of AGE-RAGE play causative roles in various aging-related diseases and alcohol-mediated tissue injuries by interfering with cell signaling pathways and forming adducts with cellular macromolecules, contributing to their inactivation and pathophysiology in many tissues/organs. These suggest biological connections between AGEs and alcohol adduct formation in relation to alcohol-mediated inflammation, gut leakiness, and multiorgan damage. In addition, the information described in this review can be useful to understand the underlying mechanisms of 


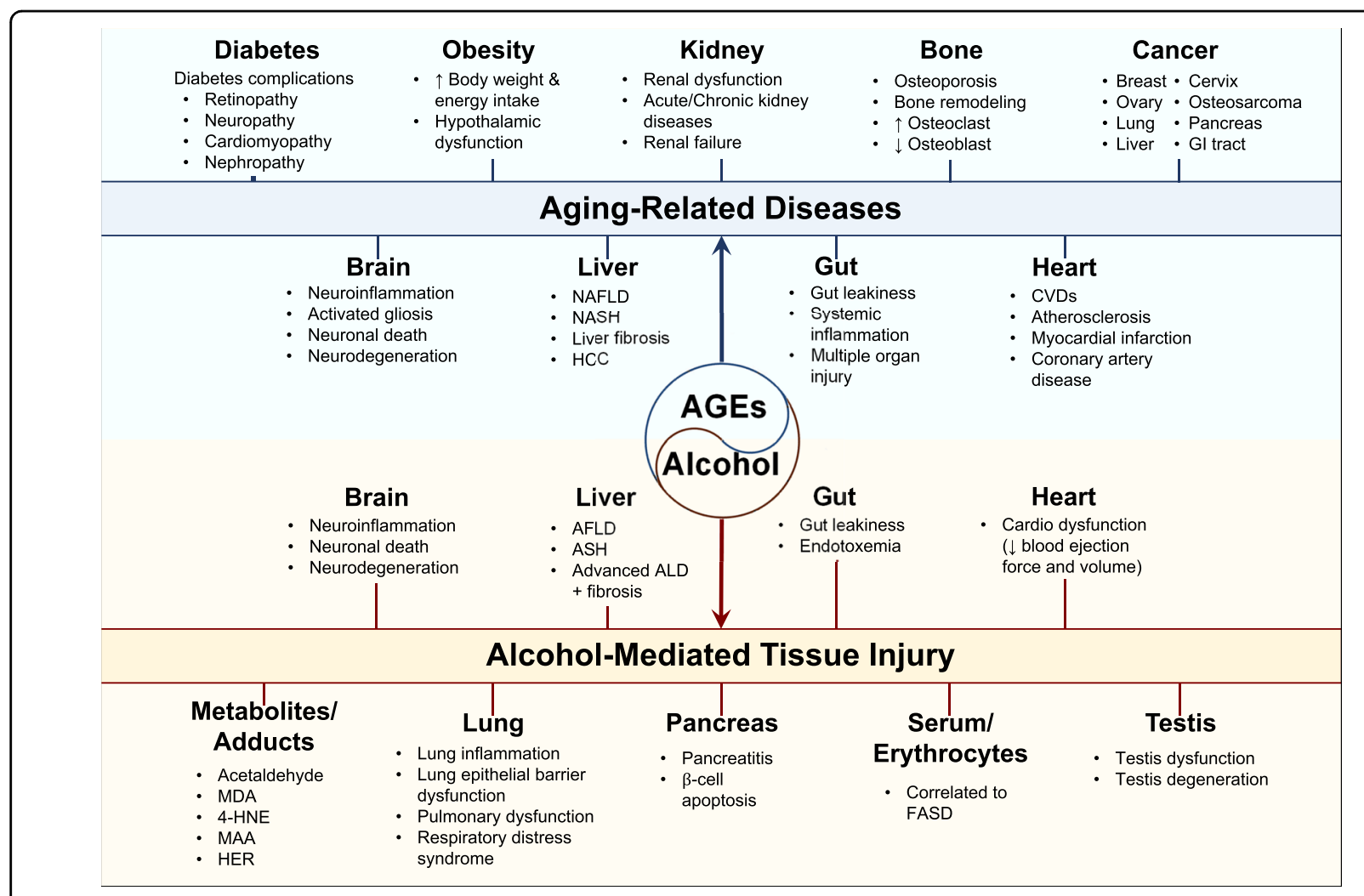

Fig. 2 Overview of the causative functions of AGEs in aging-related diseases and alcohol-mediated multiorgan dysfunction or damage. AGEs can be produced endogenously and exogenously. The accumulation of AGEs and the interaction of AGE-RAGE play causative roles in various aging-related diseases and alcohol-mediated tissue injuries by interfering with cell signaling pathways and forming adducts with cellular macromolecules, contributing to their inactivation and pathophysiology in many tissues/organs. These suggest biological connections between AGEs and alcohol adduct formation in relation to alcohol-mediated inflammation, gut leakiness, and multiorgan damage.

various diseases caused by alcohol intake, nonalcoholic substances, environmental risk factors, genetic mutations, and aging. These mechanistic insights can serve as a springboard for future translational applications for both the prevention and treatment of diverse disease states.

\section{Funding}

This research was supported by the Intramural Program Research Fund of the National Institute of Alcohol Abuse and Alcoholism, National Institutes of Health. Y.Q. was supported by Shanghai General Hospital, Shanghai Jiao Tong University School of Medicine, Shanghai, China.

\section{Author details}

'Section of Molecular Pharmacology and Toxicology, Laboratory of Membrane Biochemistry and Biophysics, National Institute on Alcohol Abuse and Alcoholism, 9000 Rockville Pike, Bethesda, MD 20892, USA. ${ }^{2}$ Neuroapoptosis Drug Discovery Laboratory, Department of Neurosurgery, Brigham and Women's Hospital, Harvard Medical School, 60 Fenwood Road, Boston, MA 02115, USA. ${ }^{3}$ Department of Food Science and Nutrition, Aging and Dementia Research Group, College of Agricultural and Marine Sciences, Sultan Qaboos University, Al-Khoud, Muscat, Oman. ${ }^{4}$ Aging and Dementia Research Group, Sultan Qaboos University, Muscat, Oman

\section{Author contributions}

W.R. conceptualization and original draft preparation; Y.Q., X.W., and M.M.E. manuscript review and editing; B.J.S. conceptualization, review and editing, and supervision.

\section{Conflict of interest}

The authors declare that they have no conflict of interest.

\section{Publisher's note}

Springer Nature remains neutral with regard to jurisdictional claims in published maps and institutional affiliations.

Received: 15 November 2020 Revised: 14 December 2020 Accepted: 15 December 2020.

Published online: 10 February 2021

\section{References}

1. Goldberg, T. et al. Advanced glycoxidation end products in commonly consumed foods. J. Am. Dietetic Assoc. 104, 1287-1291 (2004).

2. Henning, C. \& Glomb, M. A. Pathways of the Maillard reaction under physiological conditions. Glycoconj. J. 33, 499-512 (2016).

3. Uribarri, J. et al. Circulating glycotoxins and dietary advanced glycation endproducts: two links to inflammatory response, oxidative stress, and aging. J. Gerontol. A Biol. Sci. Med Sci. 62, 427-433 (2007). 
4. Byun, K. et al. Advanced glycation end-products produced systemically and by macrophages: a common contributor to inflammation and degenerative diseases. Pharmacol. Therapeutics 177, 44-55 (2017).

5. Abate, G., Marziano, M., Rungratanawanich, W., Memo, M. \& Uberti, D. Nutrition and AGE-ing: focusing on Alzheimer's disease. Oxid. Med. Cell. Longev. 2017, 1-10 (2017).

6. Jamal, M. et al. in Neuroscience of Alcohol (ed Victor R. Preedy) 39-46 (Academic Press, 2019).

7. NIAAA. Alcohol Facts and Statistics. The National Institute on Alcohol Abuse and Alcoholism (NIAAA) https:/www.niaaa.nih.gov/sites/default/files/ AlcoholFactsAndStats.pdf (2020).

8. Centers for Disease Control and Prevention, Health, United States, With Special Feature on Socioeconomic Status and Health. U.S. Department of Health and Human Services, https://nww.cdc.gov/nchs/data/hus/hus11.pdf (2012).

9. Sacks, J. J., Gonzales, K. R., Bouchery, E. E., Tomedi, L. E. \& Brewer, R. D. 2010 national and state costs of excessive alcohol consumption. Am. J. preventive Med. 49, e73-e79 (2015)

10. Asrani, S. K., Larson, J. J., Yawn, B., Therneau, T. M. \& Kim, W. R. Underestimation of liver-related mortality in the United States. Gastroenterology 145, 375-382.e371-372 (2013).

11. Brust, J. C. Ethanol and cognition: indirect effects, neurotoxicity and neuroprotection: a review. Int. J. Environ. Res. Public Health 7, 1540-1557 (2010).

12. Rhee, S. Y. \& Kim, Y. S. The role of advanced glycation end products in diabetic vascular complications. Diabetes Metab. J. 42, 188-195 (2018).

13. Peppa, M., Uribarri, J. \& Vlassara, H. Glucose, advanced glycation end products, and diabetes complications: what is new and what works. Clin. Diabetes 21, 186 (2003).

14. Aragno, M. \& Mastrocola, R. Dietary sugars and endogenous formation of advanced glycation endproducts: emerging mechanisms of disease. Nutrients 9, E385 (2017)

15. Kikuchi, S. et al. Glycation-a sweet tempter for neuronal death. Brain Res. Brain Res. Rev. 41, 306-323 (2003).

16. Zhang, Q., Ames, J. M., Smith, R. D., Baynes, J. W. \& Metz, T. O. A perspective on the Maillard reaction and the analysis of protein glycation by mass spectrometry: probing the pathogenesis of chronic disease. J. Proteome Res 8, 754-769 (2009).

17. Thornalley, P. J. Pharmacology of methylglyoxal: formation, modification of proteins and nucleic acids, and enzymatic detoxification-a role in pathogenesis and antiproliferative chemotherapy. Gen. Pharmacol. 27, 565-573 (1996).

18. Yan, S. F., Ramasamy, R. \& Schmidt, A. M. Mechanisms of disease: advanced glycation end-products and their receptor in inflammation and diabetes complications. Nat. Clin. Pract. Endocrinol. Metab. 4, 285-293 (2008).

19. Luevano-Contreras, C. \& Chapman-Novakofski, K. Dietary advanced glycation end products and aging. Nutrients 2, 1247-1265 (2010).

20. Lund, M. N. \& Ray, C. A. Control of Maillard reactions in foods: strategies and chemical mechanisms. J. Agric. Food Chem. 65, 4537-4552 (2017).

21. Nowotny, K., Schroter, D., Schreiner, M. \& Grune, T. Dietary advanced glycation end products and their relevance for human health. Ageing Res. Rev. 47 55-66 (2018)

22. Delgado-Andrade, C. Carboxymethyl-lysine: thirty years of investigation in the field of AGE formation. Food Funct. 7, 46-57 (2016).

23. Cerami, C. et al. Tobacco smoke is a source of toxic reactive glycation products. Proc. Natl Acad. Sci. USA 94, 13915-13920 (1997).

24. Vlassara, H. \& Uribarri, J. Glycoxidation and diabetic complications: modern lessons and a warning? Rev. Endocr. Metab. Disord. 5, 181-188 (2004).

25. Chan, C. M. et al. Methylglyoxal induces cell death through endoplasmic reticulum stress-associated ROS production and mitochondrial dysfunction. J. Cell. Mol. Med. 20, 1749-1760 (2016).

26. Yamabe, S. et al. Intracellular accumulation of advanced glycation end products induces apoptosis via endoplasmic reticulum stress in chondrocytes. FEBS J. 280, 1617-1629 (2013)

27. Kontaxi, C., Piccardo, P. \& Gill, A. C. Lysine-directed post-translational modifications of Tau protein in Alzheimer's disease and related tauopathies. Front. Mol. Biosci. 4, 1-14 (2017)

28. Kuhla, B. et al. Effect of pseudophosphorylation and cross-linking by lipid peroxidation and advanced glycation end product precursors on tau aggregation and filament formation. J. Biol. Chem. 282, 6984-6991 (2007).

29. Singh, V. P., Bali, A., Singh, N. \& Jaggi, A. S. Advanced glycation end products and diabetic complications. Korean J. Physiol. Pharmacol. 18, 1-14 (2014).
30. Forbes, J. M., Cooper, M. E., Oldfield, M. D. \& Thomas, M. C. Role of advanced glycation end products in diabetic nephropathy. J. Am. Soc. Nephrology: JASN 14, S254-S258 (2003).

31. Turner, D. P. Advanced glycation end-products: a biological consequence of lifestyle contributing to cancer disparity. Cancer Res. 75, 1925-1929 (2015).

32. Rojas, A., Anazco, C., Gonzalez, I. \& Araya, P. Extracellular matrix glycation and receptor for advanced glycation end-products activation: a missing piece in the puzzle of the association between diabetes and cancer. Carcinogenesis 39, 515-521 (2018).

33. Genuth, S. et al. Skin advanced glycation end products glucosepane and methylglyoxal hydroimidazolone are independently associated with longterm microvascular complication progression of type 1 diabetes. Diabetes $\mathbf{6 4}$ 266-278 (2015).

34. Rondeau, P. \& Bourdon, E. The glycation of albumin: structural and functional impacts. Biochimie 93, 645-658 (2011).

35. Sessa, L. et al. The receptor for advanced glycation end-products (RAGE) is only present in mammals, and belongs to a family of cell adhesion molecules (CAMs). Plos One 9, e86903 (2014).

36. Choi, B. R. et al. Increased expression of the receptor for advanced glycation end products in neurons and astrocytes in a triple transgenic mouse model of Alzheimer's disease. Exp. Mol. Med. 46, 1-10 (2014).

37. Chaudhuri, J. et al. The role of advanced glycation end products in aging and metabolic diseases: bridging association and causality. Cell Metab. 28 337-352 (2018)

38. Wautier, M.P., Guillausseau, P.-J. \& Wautier, J.-L. Activation of the receptor for advanced glycation end products and consequences on health. Diabetes Metab. Syndrome: Clin. Res. Rev. 11, 305-309 (2017).

39. Senatus, L. M. \& Schmidt, A. M. The AGE-RAGE axis: implications for ageassociated arterial diseases. Front. Genet. 8, 1-10 (2017).

40. Xue, J. et al. The receptor for advanced glycation end products (RAGE) specifically recognizes methylglyoxal-derived AGEs. Biochemistry $\mathbf{5 3}$, 3327-3335 (2014).

41. Bongarzone, S., Savickas, V., Luzi, F. \& Gee, A. D. Targeting the receptor for advanced glycation endproducts (RAGE): a medicinal chemistry perspective. J. Medicinal Chem. 60, 7213-7232 (2017).

42. Dhumale, S. S., Waghela, B. N. \& Pathak, C. Quercetin protects necrotic insult and promotes apoptosis by attenuating the expression of RAGE and its ligand HMGB1 in human breast adenocarcinoma cells. IUBMB Life 67, 361-373 (2015).

43. Donato, R. RAGE: a single receptor for several ligands and different cellular responses: the case of certain S100 proteins. Curr. Mol. Med. 7, 711-724 (2007)

44. Jeong, J. et al. Soluble RAGE attenuates Angll-induced endothelial hyperpermeability by disrupting HMGB1-mediated crosstalk between AT1R and RAGE. Exp. Mol. Med. 51, 1-15 (2019).

45. Miyazaki, A., Nakayama, H. \& Horiuchi, S. Scavenger receptors that recognize advanced glycation end products. Trends Cardiovasc. Med. 12, 258-262 (2002).

46. Ott, C. et al. Role of advanced glycation end products in cellular signaling Redox Biol. 2, 411-429 (2014)

47. Roshandel, D. et al. DNA methylation age calculators reveal association with diabetic neuropathy in type 1 diabetes. Clin. Epigenetics 12, 1-16 (2020).

48. Le Bagge, S., Fotheringham, A. K., Leung, S. S. \& Forbes, J. M. Targeting the receptor for advanced glycation end products (RAGE) in type 1 diabetes. Med. Res. Rev. 1-20, https://doi.org/10.1002/med.21654 (2020).

49. Egana-Gorrono, L. et al. Receptor for advanced glycation end products (RAGE) and mechanisms and therapeutic opportunities in diabetes and cardiovascular disease: insights from human subjects and animal models. Front. Cardiovasc. Med. 7, 1-15 (2020).

50. Yang, P., Feng, J., Peng, Q., Liu, X. \& Fan, Z. Advanced glycation end products: potential mechanism and therapeutic target in cardiovascular complications under diabetes. Oxid. Med. Cell. Longev. 2019, 1-12 (2019).

51. Sergi, D. et al. Mitochondrial (Dys)function and insulin resistance: from pathophysiological molecular mechanisms to the impact of diet. Front Physiol. 10, 1-20 (2019).

52. Lin, N., Zhang, H. \& Su, Q. Advanced glycation end-products induce injury to pancreatic beta cells through oxidative stress. Diabetes Metab. 38, 250-257 (2012).

53. Song, B. J. et al. Mitochondrial dysfunction and tissue injury by alcohol, high fat, nonalcoholic substances and pathological conditions through posttranslational protein modifications. Redox Biol. 3, 109-123 (2014). 
54. You, J. et al. Advanced glycation end products impair glucose-stimulated insulin secretion of a pancreatic beta-cell line INS-1-3 by disturbance of microtubule cytoskeleton via p38/MAPK activation. J. Diabetes Res. 2016 1-10 (2016).

55. Uribarri, J. et al. Restriction of advanced glycation end products improves insulin resistance in human type 2 diabetes: potential role of AGER1 and SIRT1. Diabetes Care 34, 1610-1616 (2011).

56. $\mathrm{Xu}, \mathrm{J}$. et al. Involvement of advanced glycation end products in the pathogenesis of diabetic retinopathy. Cell. Physiol. Biochem. 48, 705-717 (2018).

57. Lim, M. et al. Induction of apoptosis of Beta cells of the pancreas by advanced glycation end-products, important mediators of chronic complications of diabetes mellitus. Ann. N. Y. Acad. Sci. 1150, 311-315 (2008).

58. Kosmopoulos, M., Drekolias, D., Zavras, P. D., Piperi, C. \& Papavassiliou, A. G. Impact of advanced glycation end products (AGEs) signaling in coronary artery disease. Biochim. Biophys. Acta Mol. Basis Dis. 1865, 611-619 (2019).

59. Goldin, A., Beckman, J. A., Schmidt, A. M. \& Creager, M. A. Advanced glycation end products: sparking the development of diabetic vascular injury. Circulation 114, 597-605 (2006).

60. Aleshin, A. et al. RAGE modulates myocardial injury consequent to LAD infarction via impact on JNK and STAT signaling in a murine model. Am. J. Physiol. Heart Circ. Physiol. 294, H1823-H1832 (2008).

61. Tsoporis, J. N. et al. S100B interaction with the receptor for advanced glycation end products (RAGE): a novel receptor-mediated mechanism for myocyte apoptosis postinfarction. Circ. Res. 106, 93-101 (2010).

62. Fishman, S. L., Sonmez, H., Basman, C., Singh, V. \& Poretsky, L. The role of advanced glycation end-products in the development of coronary artery disease in patients with and without diabetes mellitus: a review. Mol. Med. 24, 1-12 (2018).

63. Koska, J. et al. Advanced glycation end products, oxidation products, and incident cardiovascular events in patients with type 2 diabetes. Diabetes Care 41, 570-576 (2018)

64. Saremi, A. et al. Advanced glycation end products, oxidation products, and the extent of atherosclerosis during the va diabetes trial and follow-up study. Diabetes Care 40, 591-598 (2017).

65. Fukami, K., Taguchi, K, Yamagishi, S. \& Okuda, S. Receptor for advanced glycation endproducts and progressive kidney disease. Curr. Opin. Nephrol. Hypertension 24, 54-60 (2015).

66. Rabbani, N. \& Thornalley, P. J. Advanced glycation end products in the pathogenesis of chronic kidney disease. Kidney Int. 93, 803-813 (2018).

67. Bettiga, A. et al. The Modern Western Diet Rich in Advanced Glycation EndProducts (AGEs): an overview of its impact on obesity and early progression of renal pathology. Nutrients 11, E1748 (2019).

68. Crowley, L. E. et al. Tissue advanced glycation end product deposition after kidney transplantation. Nephron. Clin. Pract. 124, 54-59 (2013).

69. Rabbani, N., Sebekova, K., Sebekova, K., Heidland, A. \& Thornalley, P. J. Accumulation of free adduct glycation, oxidation, and nitration products follows acute loss of renal function. Kidney Int. 72, 1113-1121 (2007).

70. Frimat, M. et al. Kidney, heart and brain: three organs targeted by ageing and glycation. Clin. Sci. 131, 1069-1092 (2017).

71. Kumar Pasupulati, A., Chitra, P. S. \& Reddy, G. B. Advanced glycation end products mediated cellular and molecular events in the pathology of diabetic nephropathy. Biomol. Concepts 7, 293-309 (2016).

72. Sanajou, D., Ghorbani Haghjo, A., Argani, H. \& Aslani, S. AGE-RAGE axis blockade in diabetic nephropathy: current status and future directions. Eur. J. Pharmacol. 833, 158-164 (2018).

73. Cheng, M. et al. HMGB1 enhances the AGE-induced expression of CTGF and TGF-beta via RAGE-dependent signaling in renal tubular epithelial cells. Am. J. Nephrol. 41, 257-266 (2015).

74. Nakamura, T. et al. Circulating levels of advanced glycation end products (AGE) and interleukin-6 (IL-6) are independent determinants of serum asymmetric dimethylarginine (ADMA) levels in patients with septic shock. Pharmacol. Res. 60, 515-518 (2009).

75. Nakamura, T. et al. Positive association of serum levels of advanced glycation end products and high mobility group box-1 with asymmetric dimethylarginine in nondiabetic chronic kidney disease patients. Metab. Clin. Exp. $\mathbf{5 8}$ 1624-1628 (2009).

76. Cordova, R. et al. Dietary intake of advanced glycation end products (AGEs) and changes in body weight in European adults. Eur. J. Nutr. 1-12, https:// doi.org/10.1007/s00394-019-02129-8 (2019).
77. Gaens, K. H. et al. Nepsilon-(carboxymethyl)lysine-receptor for advanced glycation end product axis is a key modulator of obesity-induced dysregulation of adipokine expression and insulin resistance. Arteriosclerosis, Thrombosis, Vasc. Biol. 34, 1199-1208 (2014).

78. Sergi, D., Boulestin, H., Campbell, F. M. \& Williams, L. M. The role of dietary advanced glycation end products in metabolic dysfunction. Mol. Nutr. Food Res. e1900934, https://doi.org/10.1002/mnfr.201900934 (2020).

79. Clarke, B. Normal bone anatomy and physiology. Clin. J. Am. Soc. Nephrol. CJASN 3(Suppl 3), S131-S139 (2008).

80. Okazaki, K. et al. Advanced glycation end products (AGEs), but not high glucose, inhibit the osteoblastic differentiation of mouse stromal ST2 cells through the suppression of osterix expression, and inhibit cell growth and increasing cell apoptosis. Calcif. Tissue Int. 91, 286-296 (2012).

81. Liu, J. et al. AGEs induce apoptosis in rat osteoblast cells by activating the caspase-3 signaling pathway under a high-glucose environment in vitro. Appl. Biochem. Biotechnol. 178, 1015-1027 (2016).

82. Zhu, S. Y. et al. Advanced oxidation protein products induce pre-osteoblast apoptosis through a nicotinamide adenine dinucleotide phosphate oxidasedependent, mitogen-activated protein kinases-mediated intrinsic apoptosis pathway. Aging Cell 17, 1-15 (2018)

83. Li, G., Xu, J. \& Li, Z. Receptor for advanced glycation end products inhibits proliferation in osteoblast through suppression of Wnt, PI3K and ERK signaling. Biochem. Biophys. Res. Commun. 423, 684-689 (2012).

84. Zhou, Z. \& Xiong, W.-C. RAGE and its ligands in bone metabolism. Front. Biosci. 3, 768-776 (2011).

85. Lopez-Moreno, J. et al. Dietary fat quantity and quality modifies advanced glycation end products metabolism in patients with metabolic syndrome. Mol. Nutr. Food Res. 61, 1-12 (2017).

86. Chen, Y., Filipov, N. M. \& Guo, T. L. Dietary glycation products regulate immune homeostasis: early glycation products promote prostate cancer cell proliferation through modulating macrophages. Mol. Nutr. Food Res. 62, 1-9 (2018).

87. Foster, D. et al. AGE metabolites: a biomarker linked to cancer disparity? Cancer Epidemiol. Biomark. Prev. 23, 2186-2191 (2014).

88. Kang, R. et al. The expression of the receptor for advanced glycation endproducts (RAGE) is permissive for early pancreatic neoplasia. Proc. Natl Acad. Sci. USA 109, 7031-7036 (2012)

89. Nankali, M. et al. Increased expression of the receptor for advanced glycation end-products (RAGE) is associated with advanced breast cancer stage. Oncol. Res. Treat. 39, 622-628 (2016).

90. Pusterla, T. et al. Receptor for advanced glycation endproducts (RAGE) is a key regulator of oval cell activation and inflammation-associated liver carcinogenesis in mice. Hepatology 58, 363-373 (2013).

91. Nguyen, A. H., Detty, S. Q. \& Agrawal, D. K. Clinical implications of highmobility group box-1 (HMGB1) and the receptor for advanced glycation end-products (RAGE) in cutaneous malignancy: a systematic review. Anticancer Res. 37, 1-7 (2017).

92. Kataoka, K. et al. S100A7 promotes the migration and invasion of osteosarcoma cells via the receptor for advanced glycation end products. Oncol. Lett. 3, 1149-1153 (2012).

93. Brownlee, M. Negative consequences of glycation. Metab. Clin. Exp. 49, 9-13 (2000).

94. Su, S., Chien, M., Lin, C., Chen, M. \& Yang, S. RAGE gene polymorphism and environmental factor in the risk of oral cancer. J. Dent. Res. 94, 403-411 (2015).

95. Gentile, C. L. \& Weir, T. L. The gut microbiota at the intersection of diet and human health. Science 362, 776-780 (2018).

96. Dinan, T. G. \& Cryan, J. F. Gut-brain axis in 2016: brain-gut-microbiota axis mood, metabolism and behaviour. Nat. Rev. Gastroenterol. Hepatol. 14, 69-70 (2017).

97. Tuohy, K. M. et al. Metabolism of Maillard reaction products by the human gut microbiota-implications for health. Mol. Nutr. Food Res. 50, 847-857 (2006).

98. Qu, W. et al. Dietary advanced glycation end products modify gut microbial composition and partially increase colon permeability in rats. Mol. Nutr. Food Res. 61, 1-14 (2017).

99. Zhao, D. et al. Comparison of free and bound advanced glycation end products in food: a review on the possible influence on human health. J. Agric. Food Chem. 67, 14007-14018 (2019). 
100. Yacoub, R. et al. Advanced glycation end products dietary restriction effects on bacterial gut microbiota in peritoneal dialysis patients; a randomized open label controlled trial. PloS One 12, e0184789 (2017).

101. Alam, M. Z., Alam, Q., Kamal, M. A., Abuzenadah, A. M. \& Haque, A. A possible link of gut microbiota alteration in type 2 diabetes and Alzheimer's disease pathogenicity: an update. CNS Neurol. Disord. Drug Targets 13, 383-390 (2014).

102. de la Monte, S. M. \& Kril, J. J. Human alcohol-related neuropathology. Acta Neuropathol. 127, 71-90 (2014).

103. Srikanth, V. et al. Advanced glycation endproducts and their receptor RAGE in Alzheimer's disease. Neurobiol. Aging 32, 763-777 (2011).

104. Sharma, A. et al. Advanced glycation end products and protein carbonyl levels in plasma reveal sex-specific differences in Parkinson's and Alzheimer's disease. Redox Biol. 34, 101546 (2020).

105. Wang, C.-Y. et al. Trientine reduces BACE1 activity and mitigates amyloidosis via the AGE/RAGE/NF-KB pathway in a transgenic mouse model of Alzheimer's disease. Antioxid. Redox Signal 19, 2024-2039 (2013).

106. Gasparotto, J. et al. Systemic inflammation changes the site of RAGE expression from endothelial cells to neurons in different brain areas. Mol. Neurobiol. 56, 3079-3089 (2019).

107. Gasparotto, J. et al. Receptor for advanced glycation end products mediates sepsis-triggered amyloid-beta accumulation, Tau phosphorylation, and cognitive impairment. J. Biol. Chem. 293, 226-244 (2018).

108. Byun, K. et al. Activated microglial cells synthesize and secrete AGE-albumin. Anat. Cell Biol. 45, 47-52 (2012).

109. Chen, K, Maley, J. \& Yu, P. H. Potential inplications of endogenous aldehydes in beta-amyloid misfolding, oligomerization and fibrillogenesis. J. Neurochem. 99, 1413-1424 (2006)

110. Wong, A. et al. Advanced glycation endproducts co-localize with inducible nitric oxide synthase in Alzheimer's disease. Brain Res. 920, 32-40 (2001).

111. Byun, $\mathrm{K}$. et al. Induction of neuronal death by microglial AGE-albumin: implications for Alzheimer's disease. PloS One 7, 1-11 (2012).

112. Bortolotto, V. \& Grilli, M. Every cloud has a silver lining: proneurogenic effects of abeta oligomers and HMGB-1 via activation of the RAGE-NF-kappaB axis. CNS Neurol. Disord. Drug Targets 16, 1066-1079 (2017).

113. Origlia, N. et al. Microglial receptor for advanced glycation end productdependent signal pathway drives beta-amyloid-induced synaptic depression and long-term depression impairment in entorhinal cortex. J. Neurosci. 30, 11414-11425 (2010).

114. Uchiki, T. et al. Glycation-altered proteolysis as a pathobiologic mechanism that links dietary glycemic index, aging, and age-related disease (in nondiabetics). Aging Cell 11, 1-13 (2012)

115. Guerrero, E., Vasudevaraju, P., Hegde, M. L., Britton, G. B. \& Rao, K. S. Recent advances in alpha-synuclein functions, advanced glycation, and toxicity: implications for Parkinson's disease. Mol. Neurobiol. 47, 525-536 (2013).

116. Munch, G. et al. Crosslinking of alpha-synuclein by advanced glycation endproducts-an early pathophysiological step in Lewy body formation? J. Chem. Neuroanat. 20, 253-257 (2000).

117. Sathe, K. et al. S100B is increased in Parkinson's disease and ablation protects against MPTP-induced toxicity through the RAGE and TNF-alpha pathway. Brain J. Neurol. 135, 3336-3347 (2012).

118. Abdelsalam, R. M. \& Safar, M. M. Neuroprotective effects of vildagliptin in rat rotenone Parkinson's disease model: role of RAGE-NFkappaB and Nrf2antioxidant signaling pathways. J. Neurochem. 133, 700-707 (2015).

119. Bayarsaikhan, E. et al. Microglial AGE-albumin is critical for neuronal death in Parkinson's disease: a possible implication for theranostics. Int. J. Nanomed. 10 (Spec Iss), 281-292 (2015).

120. Sebekova, K., Kupcova, V., Schinzel, R. \& Heidland, A. Markedly elevated levels of plasma advanced glycation end products in patients with liver cirrhosis amelioration by liver transplantation. J. Hepatol. 36, 66-71 (2002).

121. Fernando, D. H., Forbes, J. M., Angus, P. W. \& Herath, C. B. Development and progression of non-alcoholic fatty liver disease: the role of advanced glycation end products. Int. J. Mol. Sci. 20, 1-19 (2019).

122. Sakasai-Sakai, A., Takata, T., Takino, J. I. \& Takeuchi, M. Impact of intracellular glyceraldehyde-derived advanced glycation end-products on human hepatocyte cell death. Sci. Rep. 7, 1-11 (2017)

123. Gaens, K. H. et al. Endogenous formation of Nepsilon-(carboxymethyl))lysine is increased in fatty livers and induces inflammatory markers in an in vitro model of hepatic steatosis. J. Hepatol. 56, 647-655 (2012).

124. Leung, C. et al. Dietary glycotoxins exacerbate progression of experimental fatty liver disease. J. Hepatol. 60, 832-838 (2014).
125. Rolo, A. P., Teodoro, J. S. \& Palmeira, C. M. Role of oxidative stress in the pathogenesis of nonalcoholic steatohepatitis. Free Radic. Biol. Med. 52, 59-69 (2012).

126. Jiang, J. X. et al. Advanced glycation endproducts induce fibrogenic activity in nonalcoholic steatohepatitis by modulating TNF-alpha-converting enzyme activity in mice. Hepatology 58, 1339-1348 (2013).

127. Fehrenbach, H., Weiskirchen, R., Kasper, M. \& Gressner, A. M. Up-regulated expression of the receptor for advanced glycation end products in cultured rat hepatic stellate cells during transdifferentiation to myofibroblasts. Hepatology 34, 943-952 (2001).

128. Leung, C. et al. Dietary advanced glycation end-products aggravate non-alcoholic fatty liver disease. World J. Gastroenterol. 22, 8026-8040 (2016).

129. Hiwatashi, K. et al. A novel function of the receptor for advanced glycation end-products (RAGE) in association with tumorigenesis and tumor differentiation of HCC. Ann. Surg. Oncol. 15, 923-933 (2008).

130. Takino, J., Yamagishi, S. \& Takeuchi, M. Glycer-AGEs-RAGE signaling enhances the angiogenic potential of hepatocellular carcinoma by upregulating VEGF expression. World J. Gastroenterol. 18, 1781-1788 (2012).

131. Yang, Y. et al. Pioglitazone, a PPARgamma agonist, inhibits growth and invasion of human hepatocellular carcinoma via blockade of the rage signaling. Mol. Carcinog. 54, 1584-1595 (2015).

132. Purohit, V., Gao, B. \& Song, B. J. Molecular mechanisms of alcoholic fatty liver Alcohol. Clin. Exp. Res. 33, 191-205 (2009).

133. Thiele, G. M., Klassen, L. W. \& Tuma, D. J. Formation and immunological properties of aldehyde-derived protein adducts following alcohol consumption. Methods Mol. Biol. 447, 235-257 (2008).

134. Zakhari, S. Ovenview: how is alcohol metabolized by the body? Alcohol Res. Health. 29, 245-254 (2006).

135. Lieber, C. S. Microsomal ethanol-oxidizing system (MEOS): the first 30 years (1968-1998)-a review. Alcohol. Clin. Exp. Res. 23, 991-1007 (1999).

136. Yun, J.W. et al. Binge alcohol promotes hypoxic liver injury through a CYP2E1-HIF-1a-dependent apoptosis pathway in mice and humans. Free Radic. Biol. Med. 77, 183-194 (2014).

137. Jeong, K-S. et al. Cytochrome P450 2E1 (CYP2E1)-dependent production of a 37-kDa acetaldehyde-protein adduct in the rat liver. Arch. Biochem. Biophys. 384, 81-87 (2000)

138. Cederbaum, A. I., Lu, Y. \& Wu, D. Role of oxidative stress in alcohol-induced liver injury. Arch. Toxicol. 83, 519-548 (2009).

139. Abdelmegeed, M. A. et al. Critical role of cytochrome P450 2E1 (CYP2E1) in the development of high fat-induced non-alcoholic steatohepatitis. J. Hepatol. 57, 860-866 (2012).

140. Knockaert, L., Descatoire, V., Vadrot, N., Fromenty, B. \& Robin, M. A. Mitochondrial CYP2E1 is sufficient to mediate oxidative stress and cytotoxicity induced by ethanol and acetaminophen. Toxicol. Vitro 25, 475-484 (2011).

141. Leung, T. M. \& Nieto, N. CYP2E1 and oxidant stress in alcoholic and nonalcoholic fatty liver disease. J. Hepatol. 58, 395-398 (2013).

142. Song, B. J., Akbar, M., Jo, I., Hardwick, J. P. \& Abdelmegeed, M. A. Translational implications of the alcohol-metabolizing enzymes, including cytochrome P450-2E1, in alcoholic and nonalcoholic liver disease. Adv. Pharmacol. 74, 303-372 (2015).

143. Seitz, H. K. The role of cytochrome P4502E1 in the pathogenesis of alcoholic liver disease and carcinogenesis. Chem. Biol. Interact. 316, 108918 (2020).

144. Song, B. J. et al. Contributing roles of CYP2E1 and other cytochrome P450 isoforms in alcohol-related tissue injury and carcinogenesis. Adv. Exp. Med. Biol. 1164, 73-87 (2019).

145. Klyosov, A. A., Rashkovetsky, L. G., Tahir, M. K. \& Keung, W. M. Possible role of liver cytosolic and mitochondrial aldehyde dehydrogenases in acetaldehyde metabolism. Biochemistry 35, 4445-4456 (1996).

146. Kunitoh, S. et al. Acetaldehyde as well as ethanol is metabolized by human CYP2E1. J. Pharmacol. Exp. Therapeutics 280, 527-532 (1997).

147. Zimatkin, S. M., Pronko, S. P., Vasiliou, V., Gonzalez, F. J. \& Deitrich, R. A. Enzymatic mechanisms of ethanol oxidation in the brain. Alcohol. Clin. Exp. Res. 30, 1500-1505 (2006).

148. Deng, X-s \& Deitrich, R. A. Putative role of brain acetaldehyde in ethanol addiction. Curr. Drug Abus. Rev. 1, 3-8 (2008).

149. Arizzi-LaFrance, M. N., Correa, M., Aragon, C. M. \& Salamone, J. D. Motor stimulant effects of ethanol injected into the substantia nigra pars reticulata: importance of catalase-mediated metabolism and the role of acetaldehyde. Neuropsychopharmacology 31, 997-1008 (2006). 
150. Zimatkin, S. M. \& Lindros, K. O. Distribution of catalase in rat brain: aminergic neurons as possible targets for ethanol effects. Alcohol Alcohol. 31, 167-174 (1996).

151. Hansson, T., Tindberg, N., Ingelman-Sundberg, M. \& Kohler, C. Regional distribution of ethanol-inducible cytochrome P450 IIE1 in the rat central nervous system. Neuroscience 34, 451-463 (1990).

152. Yadav, S., Dhawan, A., Singh, R. L., Seth, P. K. \& Parmar, D. Expression of constitutive and inducible cytochrome P450 2E1 in rat brain. Mol. Cell. Biochem. 286, 171-180 (2006).

153. Upadhya, S. C., Tirumalai, P. S., Boyd, M. R., Mori, T. \& Ravindranath, V. Cytochrome P4502E (CYP2E) in brain: constitutive expression, induction by ethanol and localization by fluorescence in situ hybridization. Arch. Biochem Biophys. 373, 23-34 (2000).

154. Anandatheerthavarada, H. K. et al. Induction of brain cytochrome P-450llE1 by chronic ethanol treatment. Brain Res. 601, 279-285 (1993).

155. Montoliu, C., Valles, S., Renau-Piqueras, J. \& Guerri, C. Ethanol-induced oxygen radical formation and lipid peroxidation in rat brain: effect of chronic alcohol consumption. J. Neurochem. 63, 1855-1862 (1994).

156. Montoliu, C. et al. Ethanol increases cytochrome P4502E1 and induces oxidative stress in astrocytes. J. Neurochem. 65, 2561-2570 (1995).

157. Brzezinski, M. R., Boutelet-Bochan, H., Person, R. E., Fantel, A. G. \& Juchau, M. R. Catalytic activity and quantitation of cytochrome P-450 2E1 in prenatal human brain. J. Pharmacol. Exp. Therapeutics 289, 1648-1653 (1999).

158. Haorah, J., Knipe, B., Leibhart, J., Ghorpade, A. \& Persidsky, Y. Alcohol-induced oxidative stress in brain endothelial cells causes blood-brain barrier dysfunction. J. Leukoc. Biol. 78, 1223-1232 (2005).

159. Zhong, Y. et al. Induction of brain CYP2E1 by chronic ethanol treatment and related oxidative stress in hippocampus, cerebellum, and brainstem. Toxicology 302, 275-284 (2012).

160. Valencia-Olvera, A. C., Moran, J., Camacho-Carranza, R., Prospero-Garcia, O. \& Espinosa-Aguirre, J. J. CYP2E1 induction leads to oxidative stress and cytotoxicity in glutathione-depleted cerebellar granule neurons. Toxicol. Vitro $\mathbf{2 8}$ 1206-1214 (2014).

161. Peng, B. et al. Role of alcohol drinking in Alzheimer's disease, Parkinson's disease, and amyotrophic lateral sclerosis. Int. J. Mol. Sci. 21, https://doi.org/ 10.3390/ijms21072316 (2020).

162. Zimatkin, S. M. Histochemical study of aldehyde dehydrogenase in the rat CNS. J. Neurochem. 56, 1-11 (1991).

163. Stagos, D. et al. Aldehyde dehydrogenase 1B1: molecular cloning and characterization of a novel mitochondrial acetaldehyde-metabolizing enzyme. Drug Metab. Dispos. 38, 1679-1687 (2010).

164. Sapkota, M. \& Wyatt, A. T. Alcohol, aldehydes, adducts and airways. Biomolecules 5, 2987-3008 (2015).

165. Sachse, B., Meinl, W., Glatt, H. \& Monien, B. H. Ethanol and 4-methylpyrazole increase DNA adduct formation of furfuryl alcohol in FVB/N wild-type mice and in mice expressing human sulfotransferases 1A1/1A2. Carcinogenesis 37, 314-319 (2016).

166. Wang, M. et al. Identification of an acetaldehyde adduct in human liver DNA and quantitation as N2-ethyldeoxyguanosine. Chem. Res Toxicol. 19, 319-324 (2006).

167. Tuma, D. J. \& Casey, C. A. Dangerous byproducts of alcohol breakdown-focus on adducts. Alcohol Res. Health. 27, 285-290 (2003).

168. Freeman, T. L. et al. Recent advances in alcohol-induced adduct formation. Alcohol. Clin. Exp. Res. 29, 1310-1316 (2005)

169. Worrall, S., de Jersey, J. \& Wilce, P. A. Comparison of the formation of proteins modified by direct and indirect ethanol metabolites in the liver and blood of rats fed the lieber-de carli liquid diet. Alcohol Alcohol. 35, 164-170 (2000).

170. Tuma, D. J. Role of malondialdehyde-acetaldehyde adducts in liver injury. Free Radic. Biol. Med. 32, 303-308 (2002)

171. Niemela, O. Aldehyde-protein adducts in the liver as a result of ethanolinduced oxidative stress. Front. Biosci. 4, D506-D513 (1999).

172. Doorn, J. A., Hurley, T. D. \& Petersen, D. R. Inhibition of human mitochondrial aldehyde dehydrogenase by 4-hydroxynon-2-enal and 4-oxonon-2-enal. Chem. Res. Toxicol. 19, 102-110 (2006).

173. Galligan, J. J. et al. Oxidative stress-mediated aldehyde adduction of GRP78 in a mouse model of alcoholic liver disease: functional independence of ATPase activity and chaperone function. Free Radic. Biol. Med. 73, 411-420 (2014).

174. Sampey, B. P., Stewart, B. J. \& Petersen, D. R. Ethanol-induced modulation of hepatocellular extracellular signal-regulated kinase-1/2 activity via 4hydroxynonenal. J. Biol. Chem. 282, 1925-1937 (2007).
175. Shearn, C. T. et al. Increased carbonylation of the lipid phosphatase PTEN contributes to Akt2 activation in a murine model of early alcohol-induced steatosis. Free Radic. Biol. Med. 65, 680-692 (2013).

176. Shearn, C. T., Backos, D. S., Orlicky, D. J., Smathers-McCullough, R. L. \& Petersen, D. R. Identification of $5^{\prime}$ AMP-activated kinase as a target of reactive aldehydes during chronic ingestion of high concentrations of ethanol. J. Biol. Chem. 289, 15449-15462 (2014).

177. Hartley, D. P. \& Petersen, D. R. Co-metabolism of ethanol, ethanol-derived acetaldehyde, and 4-hydroxynonenal in isolated rat hepatocytes. Alcohol. Clin. Exp. Res. 21, 298-304 (1997).

178. Tuma, D. J., Thiele, G. M., Xu, D., Klassen, L. W. \& Sorrell, M. F. Acetaldehyde and malondialdehyde react together to generate distinct protein adducts in the liver during long-term ethanol administration. Hepatology 23, 872-880 (1996).

179. McCaskill, M. L. et al. Hybrid malondialdehyde and acetaldehyde protein adducts form in the lungs of mice exposed to alcohol and cigarette smoke. Alcohol. Clin. Exp. Res. 35, 1106-1113 (2011).

180. Patel, V. B., Worrall, S., Emery, P. W. \& Preedy, V. R. Protein adduct species in muscle and liver of rats following acute ethanol administration. Alcohol Alcohol. 40, 485-493 (2005).

181. Swaminathan, K., Clemens, D. L. \& Dey, A. Inhibition of CYP2E1 leads to decreased malondialdehyde-acetaldehyde adduct formation in VL-17A cells under chronic alcohol exposure. Life Sci. 92, 325-336 (2013).

182. Song, B. J. Ethanol-inducible cytochrome P450 (CYP2E1): biochemistry, molecular biology and clinical relevance: 1996 update. Alcohol. Clin. Exp. Res. 20, 138a-146a (1996).

183. Song, B. J., Veech, R. L., Park, S. S., Gelboin, H. V. \& Gonzalez, F. J. Induction of rat hepatic $\mathrm{N}$-nitrosodimethylamine demethylase by acetone is due to protein stabilization. J. Biol. Chem. 264, 3568-3572 (1989).

184. Roberts, B. J., Shoaf, S. E., Jeong, K. S. \& Song, B. J. Induction of CYP2E1 in liver, kidney, brain and intestine during chronic ethanol administration and withdrawal: Evidence that CYP2E1 possesses a rapid phase half-life of 6 hours or less. Biochem. Biophys. Res. Commun. 205, 1064-1071 (1994).

185. Abdelmegeed, M. A., Moon, K.-H., Chen, C., Gonzalez, F. J. \& Song, B.-J. Role of cytochrome P450 2E1 in protein nitration and ubiquitin-mediated degradation during acetaminophen toxicity. Biochem. Pharmacol. 79, 57-66 (2010).

186. Roberts, B. J., Song, B. J., Soh, Y., Park, S. S. \& Shoaf, S. E. Ethanol induces CYP2E1 by protein stabilization. Role of ubiquitin conjugation in the rapid degradation of CYP2E1. J. Biol. Chem. 270, 29632-29635 (1995).

187. Brooks, P. J. \& Theruvathu, J. A. DNA adducts from acetaldehyde: implications for alcohol-related carcinogenesis. Alcohol 35, 187-193 (2005).

188. Nakamura, K. et al. Immunohistochemical study on acetaldehyde adducts in alcohol-fed mice. Alcohol. Clin. Exp. Res. 24, 93s-96s (2000).

189. Rintala, J. et al. Evidence of acetaldehyde-protein adduct formation in rat brain after lifelong consumption of ethanol. Alcohol Alcohol. 35, 458-463 (2000).

190. Nakamura, K. et al. Acetaldehyde adducts in the brain of alcoholics. Arch Toxicol. 77, 591-593 (2003).

191. Upadhya, S. C. \& Ravindranath, V. Detection and localization of proteinacetaldehyde adducts in rat brain after chronic ethanol treatment. Alcohol Clin. Exp. Res. 26, 856-863 (2002).

192. Heymann, H. M., Gardner, A. M. \& Gross, E. R. Aldehyde-induced DNA and protein adducts as biomarker tools for alcohol use disorder. Trends Mol. Med 24, 144-155 (2018).

193. Tuma, D. J., Smith, S. L. \& Sorrell, M. F. Acetaldehyde and microtubules. Ann. N. Y. Acad. Sci. 625, 786-792 (1991).

194. Smith, S. L., Jennett, R. B., Sorrell, M. F. \& Tuma, D. J. Acetaldehyde substoichiometrically inhibits bovine neurotubulin polymerization. J. Clin. Investig. 84, 337-341 (1989).

195. Deehan, G. A. Jr, Hauser, S. R., Wilden, J. A., Truitt, W. A. \& Rodd, Z. A Elucidating the biological basis for the reinforcing actions of alcohol in the mesolimbic dopamine system: the role of active metabolites of alcohol. Front. Behav. Neurosci. 7, 1-13 (2013).

196. Iwahashi, K. et al. [Acetaldehyde adducts in the cerebral cortex of ethanol-fed mice]. Nihon Arukoru Yakubutsu lgakkai zasshi 32, 489-494 (1997)..

197. Lamarche, F., Gonthier, B., Signorini, N., Eysseric, H. \& Barret, L. Impact of ethanol and acetaldehyde on DNA and cell viability of cultured neurones. Cell Biol. Toxicol. 20, 361-374 (2004).

198. Tong, M. et al. Acetaldehyde-mediated neurotoxicity: relevance to fetal alcohol spectrum disorders. Oxid. Med. Cell. Longev. 2011, e213286 (2011). 
199. Takeuchi, M. et al. Neurotoxicity of acetaldehyde-derived advanced glycation end products for cultured cortical neurons. J. Neuropathol. Exp. Neurol. 62, 486-496 (2003).

200. Byun, K. et al. Microglial AGE-albumin is critical in promoting alcohol-induced neurodegeneration in rats and humans. PloS one $\mathbf{9}$, e104699 (2014).

201. Vetreno, R. P., Qin, L. \& Crews, F. T. Increased receptor for advanced glycation end product expression in the human alcoholic prefrontal cortex is linked to adolescent drinking. Neurobiol. Dis. 59, 52-62 (2013).

202. Ikram, M. et al. Natural dietary supplementation of curcumin protects mice brains against ethanol-induced oxidative stress-mediated neurodegeneration and memory impairment via Nrf2/TLR4/RAGE signaling. Nutrients 11, E1082 (2019).

203. Moon, K. H. et al. Inactivation of oxidized and S-nitrosylated mitochondrial proteins in alcoholic fatty liver of rats. Hepatology 44, 1218-1230 (2006).

204. Moon, K. H. et al. Oxidative inactivation of key mitochondrial proteins leads to dysfunction and injury in hepatic ischemia reperfusion. Gastroenterology 135 , 1344-1357 (2008).

205. Abdelmegeed, M. A., Moon, K. H., Hardwick, J. P., Gonzalez, F. J. \& Song, B. J. Role of peroxisome proliferator-activated receptor-alpha in fasting-mediated oxidative stress. Free Radic. Biol. Med. 47, 767-778 (2009).

206. Moon, K. H., Lee, Y. M. \& Song, B. J. Inhibition of hepatic mitochondrial aldehyde dehydrogenase by carbon tetrachloride through JNK-mediated phosphorylation. Free Radic. Biol. Med. 48, 391-398 (2010).

207. Diehl, A. M. Recent events in alcoholic liver disease V. effects of ethanol on liver regeneration. Am. J. Physiol. Gastrointest. Liver Physiol. 288, G1-G6 (2005).

208. Gao, B. \& Bataller, R. Alcoholic liver disease: pathogenesis and new therapeutic targets. Gastroenterology 141, 1572-1585 (2011).

209. Mandrekar, P., Bataller, R., Tsukamoto, H. \& Gao, B. Alcoholic hepatitis: translational approaches to develop targeted therapies. Hepatology $\mathbf{6 4}$, 1343-1355 (2016).

210. Diehl, A. M. Developmental morphogens \& recovery from alcoholic liver disease. Adv. Exp. Med. Biol. 1032, 145-151 (2018)

211. Szabo, G. Alcoholic liver disease accelerates early hepatocellular cancer in a mouse model. Adv. Exp. Med. Biol. 1032, 71-79 (2018)

212. Seitz, H. K. et al. Alcoholic liver disease. Nat. Rev. Dis. Prim. 4, 16 (2018).

213. Avila, M. A. et al. Recent advances in alcohol-related liver disease (ALD): summary of a. Gut Table Meet. Gut 69, 764-780 (2020).

214. Niemela, O. et al. Sequential acetaldehyde production, lipid peroxidation, and fibrogenesis in micropig model of alcohol-induced liver disease. Hepatology 22, 1208-1214 (1995).

215. Hayashi, N. et al. Acetaldehyde-derived advanced glycation end-products promote alcoholic liver disease. PloS One 8, e70034 (2013).

216. Niemela, O. et al. Early alcoholic liver injury: formation of protein adducts with acetaldehyde and lipid peroxidation products, and expression of CYP2E1 and CYP3A. Alcohol. Clin. Exp. Res. 22, 2118-2124 (1998).

217. Ronis, M. J. et al. Increased 4-hydroxynonenal protein adducts in male GSTA4-4/PPAR-alpha double knockout mice enhance injury during early stages of alcoholic liver disease. Am. J. Physiol. Gastrointest. liver Physiol. 308, G403-G415 (2015).

218. Fritz, K. S. \& Petersen, D. R. Exploring the biology of lipid peroxidation-derived protein carbonylation. Chem. Res Toxicol. 24, 1411-1419 (2011).

219. Shearn, C. T., Reigan, P. \& Petersen, D. R. Inhibition of hydrogen peroxide signaling by 4-hydroxynonenal due to differential regulation of Akt1 and Akt2 contributes to decreases in cell survival and proliferation in hepatocellular carcinoma cells. Free Radic. Biol. Med. 53, 1-11 (2012).

220. Mello, T., Ceni, E., Surrenti, C. \& Galli, A. Alcohol induced hepatic fibrosis: role of acetaldehyde. Mol. Asp. Med. 29, 17-21 (2008).

221. Wang, J.-H., Batey, R.-G. \& George, J. Role of ethanol in the regulation of hepatic stellate cell function. World J. Gastroenterol. 12, 6926-6932 (2006).

222. Ceni, E., Mello, T. \& Galli, A. Pathogenesis of alcoholic liver disease: role of oxidative metabolism. World J. Gastroenterol. 20, 17756-17772 (2014).

223. Willis, M. S., Klassen, L. W., Tuma, D. J., Sorrell, M. F. \& Thiele, G. M. Adduction of soluble proteins with malondialdehyde-acetaldehyde (MAA) induces antibody production and enhances T-cell proliferation. Alcohol. Clin. Exp. Res. 26, 94-106 (2002).

224. Willis, M. S., Klassen, L. W., Tuma, D. J. \& Thiele, G. M. Malondialdehydeacetaldehyde-haptenated protein induces cell death by induction of necrosis and apoptosis in immune cells. Int. Immunopharmacol. 2, 519-535 (2002).

225. Willis, M. S., Thiele, G. M., Tuma, D. J. \& Klassen, L. W. T cell proliferative responses to malondialdehyde-acetaldehyde haptenated protein are scavenger receptor mediated. Int. Immunopharmacol. 3, 1381-1399 (2003).
226. Fritz, K. S. \& Petersen, D. R. An overview of the chemistry and biology of reactive aldehydes. Free Radic. Biol. Med. 59, 85-91 (2013).

227. Galligan, J. J. et al. Protein carbonylation in a murine model for early alcoholic liver disease. Chem. Res. Toxicol. 25, 1012-1021 (2012).

228. Mottaran, E. et al. Lipid peroxidation contributes to immune reactions associated with alcoholic liver disease. Free Radic. Biol. Med. 32, 38-45 (2002)

229. Moncada, C., Torres, V., Varghese, G., Albano, E. \& Israel, Y. Ethanol-derived immunoreactive species formed by free radical mechanisms. Mol. Pharmacol. 46, 786-791 (1994).

230. Clot, P. et al. Plasma membrane hydroxyethyl radical adducts cause antibody-dependent cytotoxicity in rat hepatocytes exposed to alcohol. Gastroenterology 113, 265-276 (1997).

231. Takeuchi, M.et al. Toxic AGE (TAGE) theory for the pathophysiology of the onset/progression of NAFLD and ALD. Nutrients 9, 634 (2017)..

232. Ahmed, $\mathrm{N}$. et al. Increased protein glycation in cirrhosis and therapeutic strategies to prevent it. Ann. N. Y. Acad. Sci. 1043, 718-724 (2005).

233. Grune, T. Oxidized protein aggregates: formation and biological effects. Free Radic. Biol. Med. 150, 120-124 (2020).

234. Gauthier, T. W. et al. Fetal alcohol exposure impairs alveolar macrophage function via decreased glutathione availability. Pediatr. Res. 57, 76-81 (2005).

235. Sapkota, M. et al. Malondialdehyde-acetaldehyde (MAA) protein adducts are found exclusively in the lungs of smokers with alcohol use disorders and are associated with systemic anti-MAA antibodies. Alcohol. Clin. Exp. Res. 41 2093-2099 (2017).

236. Wyatt, T. A., Kharbanda, K. K., Tuma, D. J., Sisson, J. H. \& Spurzem, J. R. Malondialdehyde-acetaldehyde adducts decrease bronchial epithelial wound repair. Alcohol 36, 31-40 (2005).

237. Berger, J. P. et al. Malondialdehyde-acetaldehyde (MAA) adducted proteins bind to scavenger receptor A in airway epithelial cells. Alcohol 48, 493-500 (2014).

238. Duryee, M. J. et al. Scavenger receptors on sinusoidal liver endothelial cells are involved in the uptake of aldehyde-modified proteins. Mol. Pharm. 68 1423-1430 (2005).

239. Staitieh, B. S., Egea, E. E., Fan, X., Amah, A. \& Guidot, D. M. Chronic alcohol ingestion impairs rat alveolar macrophage phagocytosis via disruption of RAGE signaling. Am. J. Med. Sci. 355, 497-505 (2018).

240. Harris, B., McAlister, A., Willoughby, T. \& Sivaraman, V. Alcohol-dependent pulmonary inflammation: a role for HMGB-1. Alcohol 80, 45-52 (2019).

241. Chen, C. H. et al. Activation of aldehyde dehydrogenase-2 reduces ischemic damage to the heart. Science 321, 1493-1495 (2008).

242. Zhang, Y. \& Ren, J. ALDH2 in alcoholic heart diseases: molecular mechanism and clinical implications. Pharmacol. Therapeutics 132, 86-95 (2011).

243. Niemela, O., Parkkila, S., Worrall, S., Emery, P. W. \& Preedy, V. R. Generation of aldehyde-derived protein modifications in ethanol-exposed heart. Alcohol. Clin. Exp. Res. 27, 1987-1992 (2003).

244. Worrall, S., Richardson, P. J. \& Preedy, V. R. Experimental heart muscle damage in alcohol feeding is associated with increased amounts of reduced- and unreduced-acetaldehyde and malondialdehyde-acetaldehyde protein adducts. Addiction Biol. 5, 421-427 (2000).

245. Abdelmegeed, M. A. et al. CYP2E1 potentiates binge alcohol-induced gut leakiness, steatohepatitis, and apoptosis. Free Radic. Biol. Med. 65, 1238-1245 (2013).

246. Forsyth, C. B., Voigt, R. M. \& Keshavarzian, A. Intestinal CYP2E1: a mediator of alcohol-induced gut leakiness. Redox Biol. 3, 40-46 (2014).

247. Cho, Y. E. \& Song, B. J. Pomegranate prevents binge alcohol-induced gut leakiness and hepatic inflammation by suppressing oxidative and nitrative stress. Redox Biol. 18, 266-278 (2018).

248. Cho, Y. E., Yu, L. R., Abdelmegeed, M. A., Yoo, S. H. \& Song, B. J. Apoptosis of enterocytes and nitration of junctional complex proteins promote alcohol-induced gut leakiness and liver injury. J. Hepatol. 69 142-153 (2018).

249. Salaspuro, M. Bacteriocolonic pathway for ethanol oxidation: characteristics and implications. Ann. Med. 28, 195-200 (1996).

250. Chandrasekaran, K., Swaminathan, K., Kumar, S. M., Clemens, D. L. \& Dey, A. Increased oxidative stress and toxicity in ADH and CYP2E1 overexpressing human hepatoma VL-17A cells exposed to high glucose. Integr. Biol. 4, 550-563 (2012).

251. limuro, Y. et al. Detection of alpha-hydroxyethyl free radical adducts in the pancreas after chronic exposure to alcohol in the rat. Mol. Pharm. $\mathbf{5 0}$ 656-661 (1996). 
252. Casini, A. et al. Collagen type I synthesized by pancreatic periacinar stellate cells (PSC) co-localizes with lipid peroxidation-derived aldehydes in chronic alcoholic pancreatitis. J. Pathol. 192, 81-89 (2000).

253. Oyama, T. et al. Tissue-distribution of aldehyde dehydrogenase 2 and effects of the ALDH2 gene-disruption on the expression of enzymes involved in alcohol metabolism. Front. Biosci. 10, 951-960 (2005).

254. Kimura, S. et al. Alcohol and aldehyde dehydrogenase polymorphisms in japanese patients with alcohol-induced chronic pancreatitis. Digestive Dis. Sci. 45, 2013-2017 (2000)

255. Vonlaufen, A., Wilson, J. S., Pirola, R. C. \& Apte, M. V. Role of alcohol metabolism in chronic pancreatitis. Alcohol Res. Health. 30, 48-54 (2007).

256. Gopal, V. R. \& Indira, M. Investigations on the correlation of advanced glycated end products (AGE) associated fluorescence with blood glucose and oxidative stress in ethanol-administered diabetic rats. Exp. Toxicol. Pathol. 62 , 157-162 (2010).

257. Niemela, O. \& Israel, Y. Hemoglobin-acetaldehyde adducts in human alcohol abusers. Lab. Investig. 67, 246-252 (1992).

258. Niemelä, O., Halmesmäki, E. \& Ylikorkala, O. Hemoglobin-acetaldehyde adducts are elevated in women carrying alcohol-damaged fetuses. Alcohol. Clin. Exp. Res. 15, 1007-1010 (1991).

259. Giannessi, F. et al. Chronic alcohol administration causes expression of calprotectin and RAGE altering the distribution of zinc ions in mouse testis. Syst. Biol. Reprod. Med. 61, 18-25 (2015).

260. Healy, L. N., Pluta, L. J. \& Recio, L. Expression and distribution of cytochrome P450 2E1 in B6C3F1 mouse liver and testes. Chem. Biol. Interact. 121, 199-207 (1999).

261. Yamauchi, M. et al. Association of polymorphism in the alcohol dehydrogenase 2 gene with alcohol-induced testicular atrophy. Alcohol. Clin. Exp. Res. 25, 16S-18S (2001).

262. Lichtenstein, A. H. et al. Diet and lifestyle recommendations revision 2006: a scientific statement from the American Heart Association Nutrition Committee. Circulation 114, 82-96 (2006)

263. Bantle, J. P. et al. Nutrition recommendations and interventions for diabetes: a position statement of the American Diabetes Association. Diabetes Care $\mathbf{3 1}$ (Suppl 1), S61-S78 (2008).

264. Glade, M. J. Food, nutrition, and the prevention of cancer: a global perspective. American Institute for Cancer Research/World Cancer Research Fund, American Institute for Cancer Research, 1997. Nutrition 15, 523-526 (1999).

265. Premakumara, G. A. S., Abeysekera, W. K. S. M., Ratnasooriya, W. D., Chandrasekharan, N. V. \& Bentota, A. P. Antioxidant, anti-amylase and antiglycation potential of brans of some Sri Lankan traditional and improved rice (Oryza sativa L.) varieties. J. Cereal Sci. 58, 451-456 (2013).

266. Dearlove, R. P., Greenspan, P., Hartle, D. K., Swanson, R. B. \& Hargrove, J. L. Inhibition of protein glycation by extracts of culinary herbs and spices. J. Med. Food 11, 275-281 (2008)

267. Yeh, W. J., Hsia, S. M., Lee, W. H. \& Wu, C. H. Polyphenols with antiglycation activity and mechanisms of action: a review of recent findings. J. Food Drug Anal. 25, 84-92 (2017)

268. Chen, H., Virk, M. S. \& Chen, F. Phenolic acids inhibit the formation of advanced glycation end products in food simulation systems depending on their reducing powers and structures. Int. J. Food Sci. Nutr. 67, 400-411 (2016).

269. $\mathrm{Ma}, \mathrm{H}$. et al. Evaluation of polyphenol anthocyanin-enriched extracts of blackberry, black raspberry, blueberry, cranberry, red raspberry, and strawberry for free radical scavenging, reactive carbonyl species trapping, antiglycation, anti- $\beta$-amyloid aggregation, and microglial neuroprotective effects. Int. J. Mol. Sci. 19, 1-19 (2018)

270. Daiponmak, W., Senakun, C. \& Siriamornpun, S. Antiglycation capacity and antioxidant activities of different pigmented Thai rice. Int. J. Food Sci. Technol. 49, 1805-1810 (2014)

271. Sebekova, K. \& Somoza, V. Dietary advanced glycation endproducts (AGEs) and their health effects-PRO. Mol. Nutr. Food Res. 51, 1079-1084 (2007).

272. Uribarri, J. et al. Advanced glycation end products in foods and a practical guide to their reduction in the diet. J. Am. Dietetic Assoc. 110, 911-916.e912 (2010).

273. Swaminathan, K., Kumar, S. M., Clemens, D. L. \& Dey, A. Inhibition of CYP2E1 leads to decreased advanced glycated end product formation in high glucose treated $\mathrm{ADH}$ and CYP2E1 over-expressing VL-17A cells. Biochim. Biophys. Acta 1830, 4407-4416 (2013).

274. Kimura, Y. et al. Atorvastatin decreases serum levels of advanced glycation endproducts (AGEs) in nonalcoholic steatohepatitis (NASH) patients with dyslipidemia: clinical usefulness of AGEs as a biomarker for the attenuation of NASH. J. Gastroenterol. 45, 750-757 (2010).

275. Morimoto, M. et al. Modulation of experimental alcohol-induced liver disease by cytochrome P450 2E1 inhibitors. Hepatology 21, 1610-1617 (1995).

276. Yoshigae, Y., Sridar, C., Kent, U. M. \& Hollenberg, P. F. The inactivation of human CYP2E1 by phenethyl isothiocyanate, a naturally occurring chemopreventive agent, and its oxidative bioactivation. Drug Metab. Dispos. $\mathbf{4 1}$ 858-869 (2013).

277. Song, B. J., Moon, K. H., Olsson, N. U. \& Salem, N. Jr Prevention of alcoholic fatty liver and mitochondrial dysfunction in the rat by long-chain polyunsaturated fatty acids. J. Hepatol. 49, 262-273 (2008).

278. Choi, Y., Abdelmegeed, M. A. \& Song, B. J. Preventive effects of indole-3carbinol against alcohol-induced liver injury in mice via antioxidant, antiinflammatory, and anti-apoptotic mechanisms: role of gut-liver-adipose tissue axis. J. Nutr. Biochem. 55, 12-25 (2018).

279. Zhang, $P$. et al. Demethyleneberberine, a natural mitochondria-targeted antioxidant, inhibits mitochondrial dysfunction, oxidative stress, and steatosis in alcoholic liver disease mouse model. J. Pharmacol. Exp. Therapeutics 352 139-147 (2015).

280. Choi, Y., Abdelmegeed, M. A. \& Song, B. J. Preventive effects of dietary walnuts on high-fat-induced hepatic fat accumulation, oxidative stress and apoptosis in mice. J. Nutr. Biochem. 38, 70-80 (2016).

281. Luo, D. D. et al. Tetrahydrocurcumin and octahydrocurcumin, the primary and final hydrogenated metabolites of curcumin, possess superior hepatic-protective effect against acetaminophen-induced liver injury: role of CYP2E1 and Keap1-Nrf2 pathway. Food Chem. Toxicol. 123, 349-362 (2019).

282. Lee, H. I. et al. Low doses of curcumin protect alcohol-induced liver damage by modulation of the alcohol metabolic pathway, CYP2E1 and AMPK. Life Sci. 93, 693-699 (2013).

283. Ma, J. Q., Luo, R. Z., Jiang, H. X. \& Liu, C. M. Quercitrin offers protection against brain injury in mice by inhibiting oxidative stress and inflammation. Food Funct. 7, 549-556 (2016).

284. Gebhardt, A. C., Lucas, D., Menez, J. F. \& Seitz, H. K. Chlormethiazole inhibition of cytochrome P450 2E1 as assessed by chlorzoxazone hydroxylation in humans. Hepatology 26, 957-961 (1997).

285. Zimmerman, M. C. et al. Direct antioxidant properties of methotrexate: inhibition of malondialdehyde-acetaldehyde-protein adduct formation and superoxide scavenging. Redox Biol. 13, 588-593 (2017).

286. Lieber, C. S., Leo, M. A., Wang, X. \& Decarli, L. M. Effect of chronic alcohol consumption on Hepatic SIRT1 and PGC-1alpha in rats. Biochem. Biophys. Res. Commun. 370, 44-48 (2008).

287. Lieber, C. S., Leo, M. A., Wang, X. \& Decarli, L. M. Alcohol alters hepatic FoxO1, p53, and mitochondrial SIRT5 deacetylation function. Biochem. Biophys. Res. Commun. 373, 246-252 (2008).

288. Bonkowski, M. S. \& Sinclair, D. A. Slowing ageing by design: the rise of NAD (+) and sirtuin-activating compounds. Nat. Rev. Mol. Cell Biol. 17, 679-690 (2016).

289. Dai, H., Sinclair, D. A., Ellis, J. L. \& Steegborn, C. Sirtuin activators and inhibitors: promises, achievements, and challenges. Pharm. Ther. 188, 140-154 (2018).

290. Lee, S. E. et al. Induction of SIRT1 by melatonin improves alcohol-mediated oxidative liver injury by disrupting the CRBN-YY1-CYP2E1 signaling pathway. J. Pineal Res. 68, 1-15 (2020).

291. Munch, G., Kuhla, B., Luth, H. J., Arendt, T. \& Robinson, S. R. Anti-AGEing defences against Alzheimer's disease. Biochemical Soc. Trans. 31, 1397-1399 (2003).

292. Tsuchida, K. et al. Suppression of transforming growth factor beta and vascular endothelial growth factor in diabetic nephropathy in rats by a nove advanced glycation end product inhibitor, OPB-9195. Diabetologia 42, 579-588 (1999).

293. Savateev, K. et al. Nitrothiadiazolo[3,2-a]pyrimidines as promising antiglycating agents. Eur. J. Med. Chem. 185, 1-11 (2020). 